\title{
The role of the N'TPDase enzyme family in parasites: what do we know, and where to from here?
}

\author{
FIONA M. SANSOM* \\ Department of Biochemistry and Molecular Biology, Bio21 Molecular Science and Biotechnology Institute, \\ The University of Melbourne, Parkville, VIC 3010, Australia
}

(Received 7 November 2011; revised 12 December 2011 and 15 Fanuary 2012; accepted 20 Fanuary 2012; first published online 12 March 2012)

\begin{abstract}
SUMMARY
Nucleoside triphosphate diphosphohydrolases (NTPDases, GDA1_CD39 protein superfamily) play a diverse range of roles in a number of eukaryotic organisms. In humans NTPDases function in regulating the inflammatory and immune responses, control of vascular haemostasis and purine salvage. In yeast NTPDases are thought to function primarily in the Golgi, crucially involved in nucleotide sugar transport into the Golgi apparatus and subsequent protein glycosylation. Although rare in bacteria, in Legionella pneumophila secreted NTPDases function as virulence factors. In the last 2 decades it has become clear that a large number of parasites encode putative NTPDases, and the functions of a number of these have been investigated. In this review, the available evidence for NTPDases in parasites and the role of these NTPDases is summarized and discussed. Furthermore, the processes by which NTPDases could function in pathogenesis, purine salvage, thromboregulation, inflammation and glycoconjugate formation are considered, and the data supporting such putative roles reviewed. Potential future research directions to further clarify the role and importance of NTPDases in parasites are proposed. An attempt is also made to clarify the nomenclature used in the parasite field for the GDA1_CD39 protein superfamily, and a uniform system suggested.
\end{abstract}

Key words: nucleoside triphosphate diphosphohydrolases, NTPDases, nomenclature, enzyme.

\section{INTRODUCTION}

Nucleoside triphosphate diphosphohydrolases (NTPDases) (gene family ENTPD, GDA1_CD39 protein superfamily) are a predominantly eukaryotic family of enzymes characterized by the ability to hydrolyse a wide range of nucleoside tri- and diphosphates such as ATP and UDP. In particular a defining feature is the presence of 5 'apyrase conserved regions' (ACRs), which are conserved short stretches of amino acids containing residues essential for enzyme function. Enzyme activity is usually dependent on the presence of divalent cations such as magnesium or calcium (Handa and Guidotti, 1996; Robson et al. 2006). In mammals NTPDases are divided into 8 subclasses, termed NTPDase1-8, although for historical reasons human NTPDase1 is also usually referred to as CD39. This family of proteins is commonly found anchored in the membrane with the active site facing either the extracellular space or the lumen of the organelle in which they are located. In lower eukaryotes NTPDases are often secreted from the cell (Sansom et al. 2008b). Broadly speaking mammalian NTPDases can be

* Corresponding author: Tel: +6138344 2351. Fax: +61393481421.E-mail: fsansom@unimelb.edu.au divided into 3 groups: cell surface-located-comprising CD39/NTPDase1, NTPDase2, NTPDase3 and NTPDase8, intracellular but able to be secreted - NTPDase 5 and NTPDase6, and organelle located (and not known to be secreted) - consisting of NTPDase4 (Golgi apparatus) and NTPDase7 (intracellular membrane compartment) (Zimmermann et al. 2000). It is important to note, however, that secretion of NTPDase 5 and 6 was only observed following heterologous expression, and the significance of NTPDase secretion in mammals is unknown.

In mammals, cell surface-located NTPDases are thought to play key roles in a process known as purinergic signalling. First described nearly 40 years ago (Burnstock, 1972), purinergic signalling describes a system in which ATP and other nucleoside triphosphates (N'TPs) and nucleoside diphosphates (NDPs) act as the signalling molecules, stimulating specific purinergic (P2) receptors. Two classes of $\mathrm{P} 2$ receptors exist, namely $\mathrm{P} 2 \mathrm{X}$ receptors, comprising 7 subtypes and activated specifically by ATP, and P2Y receptors, consisting of 8 subtypes and stimulated by ATP but also by ADP, UTP, UDP, ITP and nucleotide sugars. A second receptor class of purinergic receptors, P1 receptors, is stimulated by adenosine, which is generated by $5^{\prime}$-ectonucleotidases (or ecto5 '-nucleotidases) from AMP, which in turn can be 
produced from ATP or ADP by the action of NTPDases (Burnstock, 2007; Robson et al. 2006).

Purinergic signalling plays important roles in a number of processes, including vascular haemostasis, inflammation and the immune response. CD39, the prototypic and most well-characterized member of the NTPDase family, has been shown to play a key role in blood clotting (Dwyer et al. 2004; Atkinson et al. 2006) and is also expressed on the surface of regulatory $\mathrm{T}$ cells (Treg) where it is thought to play a role in the inflammatory response (Borsellino et al. 2007; Deaglio et al. 2007). Cell surface-located NTPDases are also thought to play a role in purine salvage. In the case of organelle-located NTPDases, the main role of these enzymes appears to be in nucleotide sugar transport into the organelles in which they are located (as reviewed by Robson et al. 2006).

In this review the function of NTPDases in higher eukaryotes is discussed only as it relates to potential NTPDase function in parasites, as further detail is available in several recent and excellent reviews (Robson et al. 2006; Deaglio and Robson, 2011; Knowles, 2011). Instead the focus here is on the evidence for the presence of this enzyme family in parasites, and what data exist on the role(s) of this family of enzymes in both parasite biology and pathogenesis. In addition an attempt is made to clarify the rather confusing nomenclature currently used in the parasite field for NTPDases, and bring the terminology used into a unified framework consistent with that used by the mammalian NTPDase field.

In microbial organisms, it is only in the bacterium Legionella pneumophila that NTPDases have definitively been shown to play a role in disease pathogenesis. L. pneumophila is a gram-negative bacterium and the causative agent of Legionnaires Disease, a systemic disease characterized by pneumonia. Although very unusual for a prokaryotic organism, the genome of L. pneumophila encodes 2 NTPDases (Chien et al. 2004). Inactivation of these genes by insertion of an antibiotic resistance cassette leads to a decreased ability of the strains to replicate within macrophages and to cause disease in the mouse model of pathogenesis. Importantly, for at least 1 of the NTPDases, it was demonstrated that the NTPDase activity was essential for disease, as complementation of the mutant with an inactive form of the protein did not restore virulence (Sansom et al. 2007, 2008a,b; Vivian et al. 2010). In parasites, however, there is a distinct lack of molecular studies in which genes encoding potential NTPDases have been inactivated. Instead, as will be discussed here, evidence for the function of NTPDases in virulence relies primarily on the use of antibody and inhibitor studies. These studies, while not definitive, do suggest roles in both parasite biology and disease pathogenesis. Further complicating the study of NTPDases in parasites is the wide range of nomenclature used for the NTPDases. Terms such as 'apyrase', 'NDPase' and
'ATPDase' are in general misleading, as they do not accurately reflect the differing substrate range of this enzyme family, and are not necessarily specific for the GDA1_CD39 superfamily of proteins. The nomenclature in the mammalian field was standardized around 10 years ago (Zimmermann et al. 2000) and it is the suggestion of this author that the parasite field follow suit, to enable clear identification of NTPDases between studies, in particular when referring to NTPDases from parasites that encode multiple potential NTPDases. The proposed nomenclature is outlined in Table 1 and discussed in more detail in the following sections.

MOLECULAR EVIDENCE FOR NTPDASES IN PARASITES

From a molecular standpoint, the defining characteristic of an NTPDase is the presence of the 5 ACRs (Handa and Guidotti, 1996; Vasconcelos et al. 1996). In this section the evidence for the presence of genes encoding NTPDases in a range of parasites is reviewed, as well as the results of any biochemical studies examining the substrate range and specificity of such NTPDases. This evidence is also summarized in Table 1 for ease of reference, and Fig. 1 details the amino acid alignment of the ACRs of all parasite NTPDases discussed here. Figure 2 details the phylogenetic relationship between the parasitic NTPDases and the mammalian and yeast NTPDases, as these relationships may provide clues to the function of the uncharacterized N'TPDases.

\section{Apicomplexan parasites}

Toxoplasma gondii, the cause of the zoonotic disease toxoplasmosis, a disease of serious significance in pregnant women and the immunocompromised, encodes 3 NTPDases on its genome. However, analysis of cDNA demonstrated that only 2 of these genes are translated. Complicating the nomenclature in this species, 2 research groups simultaneously identified the NTPDases, naming them NTPase-I and NTPase-II, or NTPase3 and NTPase1 respectively (Bermudes et al. 1994; Sibley et al. 1994). Both amino acid sequences contain all 5 ACRs, demonstrating membership of the GDA1_CD39 superfamily, suggesting that it is more accurate to refer to the enzymes as NTPDases rather than simply NTPases. Thus, proposed new nomenclature referring to NTPase I (or 3) as TgNTPDase1 and NTPase II (or 1) as TgNTPDase 2 will be used here (see Table 1). The 2 $T$. gondii enzymes are very similar ( $97 \%$ identity), and biochemical techniques have been used to examine substrate range and specificity. Specifically, GSTtagged proteins were expressed and used to raise polyclonal antibodies, which were then used to pull down native NTPDases from $T$. gondii. This enabled characterization of the substrate specificity, revealing 
Table 1. Putative and known NTPDases encoded on the genomes of parasites

\begin{tabular}{|c|c|c|c|c|c|c|c|}
\hline Organism & Sequence identifier & Predicted domains* & Current nomenclature & Proposed nomenclature & Localization & Substrate preference & Reference \\
\hline T. gondii & Q27893 & SP $1-25$ & $\begin{array}{l}\text { NTPase3 } \\
\text { NTPase-I }\end{array}$ & TgNTPDase1 & Secreted (PV) & NTPs & $\begin{array}{l}\text { (Bermudes et al. 1994; } \\
\text { Sibley et al. 1994) }\end{array}$ \\
\hline T. gondii & Q27895 & SP $1-25$ & $\begin{array}{l}\text { NTPase1 } \\
\text { NTPase-II }\end{array}$ & TgNTPDase2 & Secreted (PV) & NTPs, NDPs & $\begin{array}{l}\text { (Bermudes et al. 1994; } \\
\text { Sibley et al. 1994) }\end{array}$ \\
\hline N. сапіпит & BAA31454 & SP $1-24$ & NTPase & NcNTPDase & Dense granules & NTPs & (Asai et al. 1998) \\
\hline S. neurona & AAP88692 & None & NTPase & SnNTPDase & Secreted in vitro & ATP, ADP & (Zhang et al. 2006) \\
\hline P. falciparum & XP_001348471.2 & $\begin{array}{l}\text { TMD 43-61 } \\
\text { TMD 841-863 }\end{array}$ & None & PfNTPDase & Unknown & Unknown & (Gardner et al. 2002) \\
\hline T. сruzi & AAS75599 & SP $1-35$ & NTPDase1 & TcNTPDase & Unknown & ATP, ADP & (Santos et al. 2009) \\
\hline T. brucei & XP_847211.1 & SP $1-34$ & Nucleoside phosphatase & TbNTPDase1 & Unknown & Unknown & (Berriman et al. 2005) \\
\hline T. brucei & XP_845817.1 & SP $1-34$ & Nucleoside diphosphatase & TbNTPDase2 & Unknown & Unknown & (Berriman et al. 2005) \\
\hline L. major & XP_001681917.1 & TMD 17-36 & Nucleoside diphosphatase & LmjNTPDase1 & Unknown & Unknown & (Ivens et al. 2005) \\
\hline L. major & XP_001681345.1 & SP $1-28$ & Guanosine diphosphatase & LmjNTPDase2 & Unknown & Unknown & (Ivens et al. 2005) \\
\hline L. infantum & XP_001464341 & TMD 17-39 & ATP diphosphohydrolase & LiNTPDase1 & Unknown & Unknown & (Peacock et al. 2007) \\
\hline L. infantum & XP_001463665 & SP $1-28$ & Guanosine diphosphatase & LiNTPDase2 & Unknown & Unknown & (Peacock et al. 2007) \\
\hline L. braziliensis & XP_001562178 & SP $1-32$ & Nucleoside diphosphatase & LbNTPDase1 & Unknown & Unknown & (Peacock et al. 2007) \\
\hline L. braziliensis & XP_001562788 & SP $1-35$ & Guanosine diphosphatase & LbNTPDase2 & Unknown & Unknown & (Peacock et al. 2007) \\
\hline L. donovani & CBZ̄32820.1 & TMD 17-39 & ATP diphosphohydrolase & LdNTPDase1 & Unknown & Unknown & (Downing et al. 2011) \\
\hline L. donovani & CBZ32136.1 & SP $1-28$ & Guanosine diphosphatase & LdNTPDase2 & Unknown & Unknown & (Downing et al. 2011) \\
\hline L. mexicana & CBZ25018.1 & TMD 17-36 & Nucleoside diphosphatase & LmxNTPDase1 & Unknown & Unknown & - \\
\hline L. mexicana & CBZ24328 & SP $1-28$ & Guanosine diphosphatase & LmxNTPDase2 & Unknown & Unknown & - \\
\hline S. mansoni & XP_002575548 & $\begin{array}{l}\text { TMD } 43-65 \\
\text { TMD 508-530 }\end{array}$ & SmATPDase1 & SmNTPDase1 & Parasite surface & Unknown & (Vasconcelos et al. 1996) \\
\hline S. mansoni & XP_002579239.1 & None & SmATPDase2 & SmNTPDase2 & Secreted & Unknown & (Levano-Garcia et al. 2007) \\
\hline T. vaginalis & TVAG_063220 & TMD 403-425 & NTPDaseB & TvNTPDase1 & Unknown & Unknown & (Ruckert et al. 2010) \\
\hline T. vaginalis & TVAG_167570 & TMD 389-411 & NTPDaseA & TvNTPDase2 & Unknown & Unknown & (Ruckert et al. 2010) \\
\hline T. vaginalis & TVAG_397320 & $\begin{array}{l}\text { SP } 1-23 \\
\text { TMD } 410-432\end{array}$ & None & TvNTPDase3 & Unknown & Unknown & (Carlton et al. 2007) \\
\hline T. vaginalis & TVAG_444510 & TMD 416-438 & None & TvNTPDase4 & Unknown & Unknown & (Carlton et al. 2007) \\
\hline T. vaginalis & TVAG_351590 & $\begin{array}{l}\text { SP } 1-16 \\
\text { TMD } 390-412\end{array}$ & None & TvNTPDase5 & Unknown & Unknown & (Carlton et al. 2007) \\
\hline C. albicans & XP 716635.1 & SP $1-26$ & GDA1 & GDA1 & Golgi & GDP, UDP & (Herrero et al. 2002) \\
\hline C. albicans & EEQ44905.1 & TMD 519-541 & Golgi apyrase & YND1** & Unknown & Unknown & (Jones et al. 2004) \\
\hline C. parapsilosis & CCE 44692.1 & SP $1-21$ & - & GDA1** & Unknown & Unknown & (Butler et al. 2009) \\
\hline C. parapsilosis & CCE 44390.1 & TMD 509-531 & - & YND1** & Unknown & Unknown & (Butler et al. 2009) \\
\hline C. parapsilosis & CCE44739.1 & TMD $640-659$ & - & NTPDase $3^{\#}$ & Unknown & Unknown & (Butler et al. 2009) \\
\hline C. neoformans & AAR87384.1 & None & GDA1 & GDA1 & Unknown & Unknown & (Loftus et al. 2005) \\
\hline C. neoformans & XP_571453.1 & None & Nucleoside diphosphatase & YND1** & Unknown & Unknown & (Loftus et al. 2005) \\
\hline
\end{tabular}

NTPs, nucleoside triphosphates.

NDPs, nucleoside diphosphates.

SP, signal peptide.

TMD, transmembrane domain

$\mathrm{PV}$, parasitophorous vacuole.

* Putative domains detected using simple modular architecture research tool (SMART) (http://smart.embl-heidelberg.de/).

* Terminology used here to indicate a homologue of the $S$. cerevisiae protein.

\# Terminology used here for convenience to indicate a third putative NTPDase in C.parapsilosis. 


\begin{tabular}{|c|c|c|c|c|c|}
\hline & ACR1 & ACR2 & ACR3 & ACR4 & ACR5 \\
\hline TVNTPDase 3 & DAGSSGTR & ATAGMRLL & GYEEG & GGASVQFAS & WTLG \\
\hline TVNTPDase4 & DAGSSSTR & ATAGMRLL & GYEEG & GGASAQIAA & WTLG \\
\hline TVNTPDase 1 & AGSSGTR & ATAGMRLL & GVEEG & GGASFQIAV & AIG \\
\hline TVNTPDase2 & AGSSGTR & ATAGMRLL & GVEEG & GGASFQIAL & AIG \\
\hline c.a YND1 & SGSSGSR & STAGMRLL & GSTEG & GGASTQIAF & TLG \\
\hline$c \cdot p$ YND1 & SGSSGSR & STAGMRLL & GSTEG & GGASTQIAF & TLG \\
\hline TCNTPDase & AGSTGSR & ATAGLRRI & GWEEG & GGGSTQIVM & ALG \\
\hline TbNTPDase1 & AGSTGSR & ATAGLRRI & GREEG & GGGSTQVVM & TLG \\
\hline LiNTPDase2 & IGSTGNR & ATAGLRML & ACEEG & GGGSTQIVF & SLG \\
\hline LdNTPDase2 & IGSTGNR & ATAGLRML & ACEEG & GGGSTQIVF & \\
\hline LmNTPDase2 & IGSTGNR & ATAGLRML & ACEEG & GGGSTQIVF & SLG \\
\hline LmxNTPDase 2 & IGSTGNR & ATAGLRML & PREEG & GGGSTQIVF & SLG \\
\hline LbNTPDase2 & IGSTGNR & ATAGLRML & SHEEG & GSTQIVF & PLG \\
\hline LiNTPDase1 & AGSTGSR & ATAGLRLL & GAQEG & GGASTQV & SLG \\
\hline LdNTPDase1 & DAGSTGSR & ATAGLRLL & GAQEG & GGASTQVVF & SLG \\
\hline LmNTPDase1 & DAGSTGSR & ATAGLRLL & GAQEG & GGASTQVVF & ISL \\
\hline LmxNTPDase 1 & DAGSTGSR & ATAGLRLL & GAQEG & GGASTQVVF & ISL \\
\hline LbNTPDase1 & DAGSTGSR & ATAGLRLL & GAQEG & GGASTQVVF & SL \\
\hline TbNTPDase2 & AGSTGTR & ATAGLRLL & GDEEG & GGASTQLVL & WALG \\
\hline c.a. GDA1 & AGSTGSR & GLRLL & GKDEG & GGGSTQIVF & WCLG \\
\hline c.p. GDA1 & AGSTGSR & GLRLL & GKDEG & VF & CLG \\
\hline C.n GDA1 & DAGSTGSR & ATAGLRLL & KIGEG & GGASTQIVF & ALG \\
\hline TgNTPDase1 & DAGSSSTR & STAGVRDF & GAEEG & GGASAQIVF & $Q \mathrm{QV}$ \\
\hline TgNTPDase 3 & DAGSSSTR & STAGVRDF & GAEEG & GGASAQIVF & $\mathrm{QV}$ \\
\hline NcNTPDase & DGGSSATR & STAGVRDF & GAEEG & GGASAQIVF & WHVG \\
\hline SnNTPDase & DGGSSKTQ & STAGIRDF & GEEEG & GGASMQIVL & WPIG \\
\hline TVNTPDase5 & CGSTGSR & ATAGMRLL & GQDEA & GGASFQIAQ & WTMG \\
\hline SmNTPDase2 & DAGSTGSR & ATAGLRLI & GFYEG & GGGSTQITF & WSL \\
\hline c.n. YND1 & AGSSGSR & ATAGMRLL & GEEEG & GGASTQLAF & WTL \\
\hline PfNTPDase & AGSNGTR & ATGGMRNL & GEEEG & GGSSTQITF & WTH \\
\hline SmNTPDase 1 & DAGSTSSK & ATAGMRLK & GSEEG & GGASTQIAF & WAL \\
\hline \multirow[t]{2}{*}{ C.p.NTPDase 3} & DAGSKGSR & ATAGMRLL & GDYEG & GGASTQVVF & WALG \\
\hline & $\star \star$ & & & & \\
\hline
\end{tabular}

Fig. 1. Amino acid alignment of putative and known NTPDases of parasites demonstrating the presence of the 5 crucial 'apyrase conserved regions' (ACRs) in all predicted protein sequences. Absolutely conserved residues are starred. Sequence alignment was performed using the ClustalW sequence alignment tool (http://www.ebi.ac.uk/ Tools/msa/clustalw2/) (Larkin et al. 2007; Goujon et al. 2010). Identifying numbers for amino acid sequences used in the alignment are listed in Table 1. C. a., C. albicans; C. p., C. parapsilosis; C. n., C. neoformans.

interesting differences despite the similarity of the proteins. Both NTPDases hydrolyse ATP, GTP, CTP and UTP, but TgNTPDase1 has less than 1\% of the relative activity of hydrolysis of ADP, GDP, CDP and UDP. However, it has higher NTPase activity, being $4 \cdot 5$ times more efficient at hydrolysing ATP than TgNTPDase2 (Asai et al. 1995). Intriguingly, it is an area outside the ACRs which appears to dictate substrate specificity - namely a 12-residue block of amino acids in the C-terminus of the proteins. Synthesis of protein chimeras has demonstrated that a 12-residue block of amino acids FITGREMLASID and IVTGGGMLAAIN near the C-terminus of TgNTPDase2 and TgNTPDase1 respectively (residues 488-499) alters specificity for NTPs and NDPs (Nakaar et al. 1998a). Sera from a small fraction of $T$. gondii patients can discriminate between TgNTPDase1 and TgN'TPDase 2 on the basis of these 12 residues demonstrating that the difference is antigenically distinct, although the significance of this finding is not clear (Johnson et al. 1999).

The related parasite Neospora caninum causes disease such as abortion in domestic animals, but is not thought to infect humans. The genome of $N$. caninum is not yet published, but 1 study used Southern blotting to demonstrate the presence of multiple genes encoding NTPDases (Asai et al. 1998). However, analysis of cDNA clones indicated that at least 2 genes were nearly identical, as well as confirming that the predicted proteins contain all 5 ACRs. Recombinant NcNTPDase was produced from one cDNA clone, and native NTPDase was also partially purified. Analysis of the enzyme activity demonstrated an ability to hydrolyse a wide variety of NTPs, but little activity against NDPs, consistent with the observation that NcNTPDase is most similar (69\% identity) to TgNTPDase1. Given the large difference in the range of substrates of the $2 T$. gondii NTPDases (despite being very similar in amino acid sequence) it would be interesting, once the complete genome is published, to identify which genes are actually transcribed, and if recombinant forms of each NTPDase do indeed only hydrolyse NTPs.

More recently another apicomplexan parasite Sarcocystis neurona, a cause of encephalitis in horses, was shown to possess a gene encoding an NTPDase (Zhang et al. 2006). A recombinant form of this 


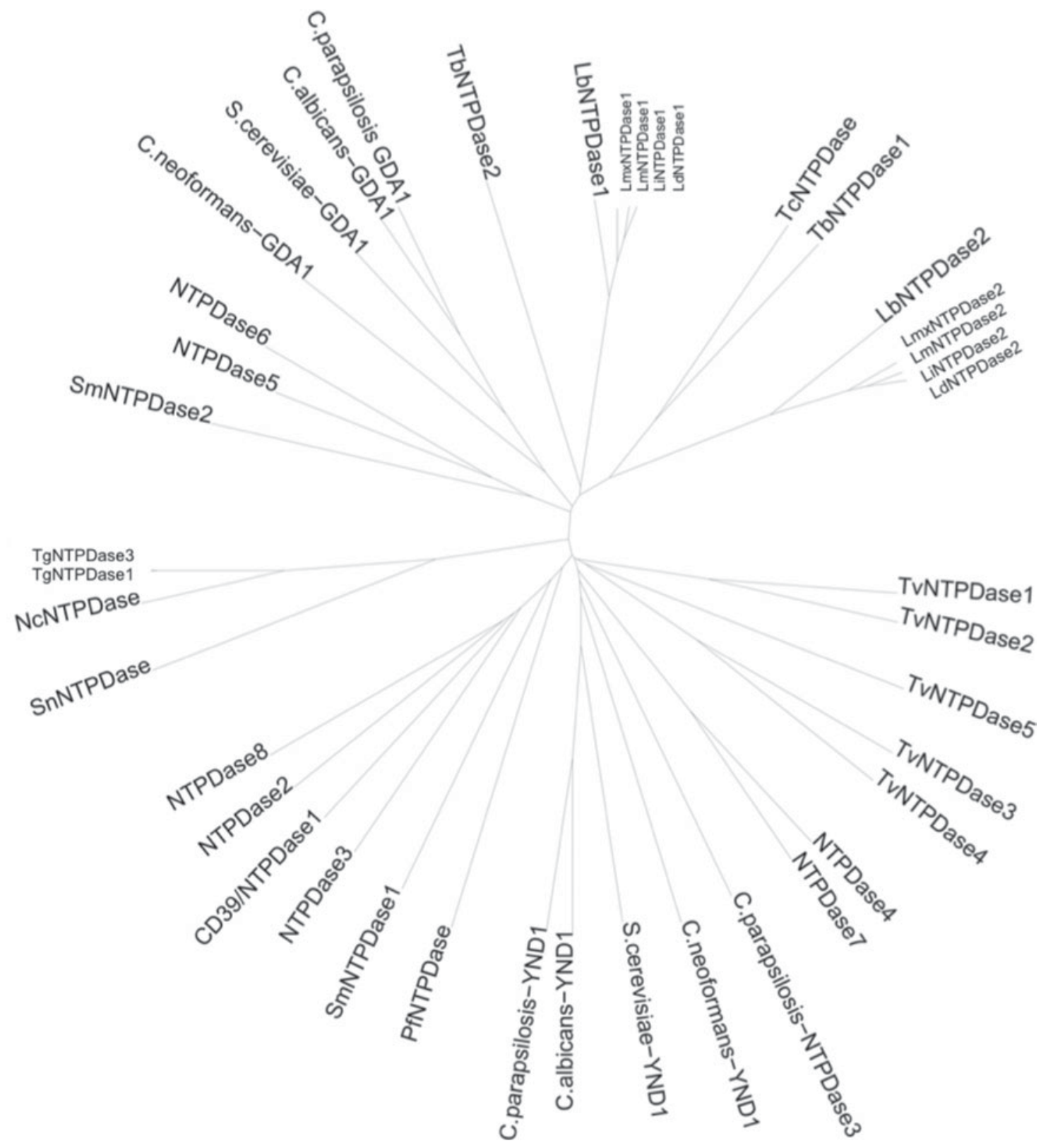

Fig. 2. Phylogenetic tree constructed from amino acid sequences of human, yeast and parasite NTPDases (sequence identifying numbers are listed in Table 1 or below). The phylogenetic tree was generated from an alignment of sequences using the ClustalW sequence alignment tool, with the resulting tree viewed and edited using the Interactive Tree of Life web tool (http://itol.embl.de/index.shtml) (Letunic and Bork, 2007, 2011). Human CD39/NTPDase1: NP_001767, human NTPDase2:NP_982293, human NTPDase3:NP_982293, human NTPDase4:NP_004892, human NTPDase5:NP_001240, human NTPDase6:NP_001238, human NTPDase7:NP_065087, human NTPDase8: NP_001028285, S. cerevisiae GDA1:NP_010872, S. cerevisiae YND1:EDN62971.

protein was produced and tested for ability to hydrolyse both ATP and ADP. Similar activity was seen against both substrates, although other NTPs and NDPs were not tested.

Finally, the genome of the important apicomplexan parasite Plasmodium falciparum, the major cause of human malaria, encodes a single NTPDase (Gardner et al. 2002). Interestingly this NTPDase appears evolutionarily distinct from the NTPDases of other apicomplexan parasites (Fig. 2), (Sansom et al. 2008b), and instead more closely related to the cell surface-located NTPDases of humans and Schistosoma mansoni. Currently no information exists as to substrate preference or activity levels of the predicted protein.

\section{Trypanosomatids}

Of the trypanosomatid parasites only the NTPDase of $T$. cruzi, the causative agent of Chagas disease, has been characterized on a molecular level. The genome of T. cruzi encodes a single predicted NTPDase 
containing all 5 ACRs. A recombinant form of this enzyme has been expressed and purified from bacteria, and the substrate specificity examined. TcNTPDase has activity against ATP and ADP, with an ATPase:ADPase ratio similar to NTPDase1/ CD39 (Santos et al. 2009). The genome of Trypanosoma brucei, the cause of African sleeping sickness, encodes 2 predicted NTPDases (Berriman et al. 2005), but no biochemical characterization has been performed. Similarly, all 5 species of Leishmania for which genome sequence information is available possess 2 predicted NTPDases (Peacock et al. 2007), but no characterization of these enzymes is available. Leishmania causes the disease known as leishmaniasis, which exists as cutaneous, mucocutaneous and visceral forms, depending on the species responsible for infection (Herwaldt, 1999). The sequenced strains represent at least 1 species responsible for each syndrome, demonstrating that NTPDases are conserved on the genome irrespective of the resulting disease syndrome. The nomenclature, particularly for the $T$. brucei and Leishmania NTPDases, is also confused. While some studies refer to ectonucleoside triphosphate diphosphohydrolase activities of, for example, L. amazonensis (Pinheiro et al. 2006), the genome annotation for the 2 NTPDases are nucleoside diphosphatase and guanosine diphosphatase (Peacock et al. 2007) which, in light of the unknown substrate specificities of these enzymes, is not necessarily accurate or informative. As both predicted proteins from T. brucei and all Leishmania species contain the $5 \mathrm{ACRs}$, it makes sense to refer to these enzymes as NTPDases, and to use this term consistently ('Table 1).

\section{Trichomonas vaginalis}

T. vaginalis is a flagellated protozoan responsible for trichomoniasis, the most common non-viral sexually transmitted disease in the world (Van der Pol, 2007). Recent studies identified 2 NTPDase orthologues on the $T$. vaginalis genome and demonstrated an effect on transcription levels, by RT-PCR, in the presence of various steroids and drugs (Giordani et al. 2010; Ruckert et al. 2010). These studies identified the proteins by BLAST searching using mammalian NTPDase sequences. However, prior BLAST searching of the translated genome (Carlton et al. 2007) using parasite N'TPDase sequences had in fact revealed 4 genes encoding predicted NTPDases (Sansom et al. 2008b) and a most recent BLAST search of the translated genome performed here reveals a total of 5 predicted NTPDases containing all 5 ACRs (Table 1, Fig. 1). However, no information on the level of enzyme activity or substrate specificity for each predicted NTPDase is currently available, nor is it known if all 5 putative NTPDases are expressed or where the NTPDases localize within the parasite.
Schistosoma mansoni

S. mansoni is a trematode responsible for intestinal schistosomiasis in humans. Purification of proteins from $S$. mansoni using antibodies to potato NTPDase and $T$. gondii NTPDase revealed 2 isoforms of NTPDases, which were both able to hydolyse ATP while one isoform had higher ADPase activity (Vasconcelos et al. 1996). The genome of S. mansoni encodes 2 predicted NTPDases, currently designated SmATPDase1 and SmATPDase2. A recombinant form of SmATPDase1 has been produced in $E$. coli and used to raise polyclonal antibodies, although the activity of the recombinant protein has not been directly tested. SmATPDase2 has also been expressed in E.coli, and recombinant forms purified by solubilization of inclusion bodies and refolding, although the activity of this protein has not been tested (LevanoGarcia et al. 2007). It is not clear which gene encodes which NTPDase isoform identified in the original study (Vasconcelos et al. 1996), and thus the specific activity of each protein against NTPs and NDPs is unknown. Given the presence of all 5 ACRs, it is most likely that the enzymes do hydrolyse other NTPs and/or NDPs, and thus are more accurately referred to as N'TPDases (Table 1).

\section{Fungi}

The genome of the non-pathogenic yeast Saccharyomyces cerevisiae encodes 2 NTPDases. These proteins, GDA1 and YND1, are located in the Golgi apparatus, and play crucial roles in glycosylation (Abeijon et al. 1993; Gao et al. 1999). Interestingly the two proteins have different membrane topologies (reviewed by Knowles, 2011), with the single transmembrane domain of YND1 located near the $\mathrm{C}$-terminus of the protein. The proteins are also not particularly closely related (Fig. 2). Deletion of either enzyme in $S$. cerevisiae results in defects in $\mathrm{N}$ - and $\mathrm{O}$-glycosylation, as well as wider defects in cell wall synthesis, and deletion of both genes is lethal (Gao et al. 1999; Knowles, 2011). A similar role for GDA1 has been identified in other species of yeast, including Schizosaccharomyces pombe (Sanchez et al. 2003) and Kluyveromyces lactis (Lopez-Avalos et al. 2001), as well as in the pathogenic yeast Candida albicans (Herrero et al.2002). C. albicans also encodes a homologue of YND1 (Figs 1 and 2), although in this species of yeast the protein has not been characterized (Jones et al. 2004). Another fungal pathogen of humans, Cryptococcus neoformans, encodes homologues of both GDA1 and YND1 (Figs 1 and 2), but these proteins have also not been studied (Loftus et al. 2005). Most interestingly, BLAST searching of the genome of another human pathogen, Candida parapsilosis, revealed 3 putative NTPDases (Butler et al. 2009). While 2 of these proteins appear to be homologues of GDA1 and YND1 (Figs 1 and 2, 
Table 1), and most likely have similar functions, the third may well play a different role. However, these proteins are also currently uncharacterized, and thus it is not known what function the third NTPDase performs.

EVIDENCE FOR THE PRESENCE OF NTPDASE

PROTEINS AND NTPDASE ACTIVITY IN PARASITES

The sequencing of a large number of parasite genomes over the last decade has revealed that many do indeed encode putative NTPDases (Table 1, Fig. 1). Additionally, for many of these parasites enzyme activity consistent with the presence of NTPDases has been observed. What, however, is often less clear is which putative NTPDase (if any) is responsible for the observed enzyme activity. While for some parasites the localization of the putative NTPDases is known, for others no studies have been undertaken. Furthermore, while the substrate specificity of some parasite N'TPDases is well characterized, for others it is unknown, or inferred from assays using whole parasites or parasite extracts. In this section the biological evidence for the presence of NTPDases in parasites and, when known, the localization of the enzymes is discussed.

\section{Apicomplexan parasites}

The use of antibodies to recombinant forms of the $T$. gondii NTPDases has enabled accurate localization of the enzymes within the parasite and during infection of the mammalian host cell. In the extracellular tachyzoite form of the parasite the NTPDases are present in dense granules, and following infection of the host cell both enzymes are secreted into the lumen of the parasitophorous vacuole (PV) (Bermudes et al. 1994; Sibley et al. 1994). The precise roles of the two enzymes during host infection are not known, but a number of studies, discussed below, implicate at least one NTPDase in virulence. Unfortunately the similarity of the genes encoding the NTPDases, as well as some evidence that TgNTPDase1 is essential for viability, appears to preclude the generation of a specific mutant (Nakaar et al. 1999), making it difficult to definitively show that either or both N'TPDases are involved in pathogenesis. Nonetheless the studies performed to date do certainly suggest a role for NTPDases in the ability of the parasite to cause disease.

Analysis of expression levels of the enzymes revealed that $\operatorname{TgNTPDase} 1$ has only low levels of expression in the bradyzoite form of the parasite (the form responsible for chronic host infection) but is highly expressed in the actively replicating tachyzoite form (Nakaar et al. 1998b). The presence of the two enzymes in virulent and non-virulent strains also implicates TgNTPDase1 in virulence, as most virulent strains of $T$. gondii possess the gene encoding
TgNTPDase1, but avirulent strains carry only the gene encoding TgNTPDase2 (Asai et al. 1995; Nakaar et al. 1998a). In the absence of the ability to make deletion mutants, antisense RNA studies demonstrated that TgNTPDase1 was dispensable for entry into host cells but required for replication once inside the host cell (Nakaar et al. 1999). These results do conflict with another study using a monoclonal antibody that inhibited both NTPDases. Pre-treatment of parasites with this antibody resulted in decreased invasion of Vero cells (Kikuchi et al. 2001), suggesting that NTPDase activity did contribute to invasion of host cells and highlighting the difficulty in interpreting studies where techniques that may have off-target effects are used. While the similarity of the genes may preclude generation of a single mutant, the proximity of the genes to each other on the chromosome may allow a double mutant to be created, and analysis of such a mutant would still provide valuable information.

There is also some evidence that TgNTPDase1 may be involved in egress from the host cell, shown by experiments examining the activation state of the enzyme. When secreted by the parasite, TgNTPDase1 remains largely oxidized, reflecting the fact that parasitic infections generate host nitric oxide and other free radicals that result in oxidative stress. If exogenous thiols are used to activate the enzyme, a rapid drop in host cell ATP occurs and the parasites exit the cell within a minute of treatment (Silverman et al. 1998). This exit requires $\mathrm{Ca}^{2+}$ ions, presumably released when ATP depletion occurs (Stommel et al. 1997). Thus the activation of secreted TgNTPDase1 must be closely regulated by the parasite. $T$. gondii secrete the reducing agent glutaredoxin (GRX) as replication increases, and GRX is able to activate TgNTPDase1 in vitro, suggesting GRX secretion by the parasite may be a way of controlling the oxidation state of TgNTPDase1 and thus implicating $\mathrm{TgNTPD}$ ase1 in a role in exit from the host (Stommel et al. 2001). All these studies implicate $T$. gondii NTPDase(s) in pathogenesis at all stages of the intracellular life cycle, suggesting that further investigation of these enzymes is warranted.

Much less is known about the biological role of the other apicomplexan NTPDases. NcNTPDase is also localized to the dense granules of the parasite and may be secreted in a similar manner to the NTPDases of $T$. gondii, consistent with the presence of a typical N-terminal signal peptide (Asai et al. 1998). Immunoblotting using polyclonal antibodies demonstrated secretion of ScNTPDase into culture supernatants in vitro, also consistent with its signal peptide. Localization studies demonstrate that ScNTPDase is expressed in an apical location on merozoites immediately following host cell invasion, but is then absent during intracellular replication before reappearing on newly formed merozoites immediately prior to exit 
from the host cell (Zhang et al. 2006). These data suggests a role in host cell exit and/or entry, or possibly that ScNTPDase is also required during extracellular survival of the parasite. It also may be that the protein is secreted during replication into the $\mathrm{PV}$, but in amounts not detected by the localization techniques used. No biological evidence exists to identify the possible role of the $P$. falciparum NTPDase, although the presence of predicted transmembrane domains on both the $\mathrm{N}$ - and $\mathrm{C}$-terminal of the protein (Table 1) suggests that, in contrast to the other apicomplexan parasites, this NTPDase is not secreted, but rather anchored in a membrane.

\section{Trypanosomatids}

The presence of $\mathrm{Mg}^{2+}$-dependent ecto-ATPase activity - that is, activity consistent with the presence of a surface-located NTPDase - was demonstrated for the intracellular parasite T. cruzi (Bisaggio et al. 2003), and a subsequent study demonstrated a range of ecto-NTPDase activities of intact parasites (Fietto et al. 2004). Most recently, T. cruzi was shown to vary its ecto-ATPase:ADPase ratio during passage in culture, and a drop in overall enzyme activity levels correlated with decreased infectivity for mammalian cells (Santos et al. 2009). However, one draw-back of this study was the inability to discern enzyme activity due to other surface-located enzymes from activity attributable to TcNTPDase. In fact, use of ARL67156, an inhibitor considered specific for NTPDases, inhibited only $30 \%$ and $50 \%$ of the observed ATPase and ADPase activity, suggesting that other classes of enzymes are responsible for some of the observed activity. Intriguingly, ARL67156 was unable to inhibit recombinant TcNTPDase, an unexpected finding, which may reflect a differing structure of TcNTPDase compared to other NTPDases which are inhibited by ARL67156, or could also relate to altered folding of the recombinant protein during expression, re-folding and purification. While such altered folding would presumably have an effect on enzyme activity, as the enzyme activity of native TcNTPDase is unknown, it is not possible to use the observed enzyme activity to demonstrate that the recombinant protein is $100 \%$ correctly folded. Despite lack of inhibition of TcNTPDase by ARL67156, treatment of parasites with ARL67156, or the non-specific NTPDase inhibitors gadolinium and suramin, resulted in decreased infectivity in vitro as well as decreased virulence in the mouse model of disease (Santos et al. 2009). It is therefore hard to distinguish from these results, however, how much of the effect on virulence is specifically related to inhibition of TcNTPDase activity. The effect on infection of non-specific inhibitors does agree with earlier work demonstrating inhibition of ecto-ATPase activity by suramin and $4,4 \phi$-diisothiocy-anostylbene $2 \notin, 2 \phi$-disulfonic acid
(DIDS) (Bernardes et al. 2000; Bisaggio et al. 2003), which resulted in a decreased number of parasites attaching to and infecting mouse peritoneal macrophages. In direct contrast, addition of $200 \mu \mathrm{M}$ ATP increased macrophage infection by $30 \%$ (Bisaggio et al. 2003). Again however, it is hard to determine the contribution of TcNTPDase to the observed effect on infection, as these inhibitors have other effects.

Earlier studies also provide some evidence for a role for NTPDase activity in parasite virulence, although again it is uncertain if the observed activity is due to TcNTPDase. Up to 20-fold higher ecto-ATPase activity has been observed in the infective trypomastigote stage compared to the epimastigote stage (Bisaggio et al. 2003; Meyer-Fernandes et al. 2004). An altered ratio of ATP:ADP hydrolysis was also observed, with an ATP:ADP hydrolysis ratio for trypomastigotes of $2: 1$, while for epimastigotes it is 1:1. Other substrates are also hydrolysed by T. cruzi, again suggesting NTPDase activity, with hydrolysis of GTP, GDP, UTP and UDP, with highest activity against GTP (Bisaggio et al. 2003).

The localization of TcNTPDase is also still unclear. An early study showed cross-reaction of a protein on the surface of the parasite with an antibody to $T$. gondii NTPDase (Fietto et al. 2004). However, the presence of a predicted $\mathrm{N}$-terminal signal peptide suggests the parasite may secrete TcNTPDase. Polyclonal antibodies to recombinant TcNTPDase do now exist, and use of these antibodies in immunofluorescence experiments may clarify the location of TcNTPDase, particularly during infection of mammalian cells. Use of other genetic techniques now available in T. cruzi (Taylor et al. 2011), including systems to epitope-tag proteins (e.g. with GFP) and to over-express proteins, may also help clarify both the location of TcNTPDase and its function.

In contrast to T. cruzi, T. brucei is an extracellular pathogen that in mammals replicates in the blood stream (Matthews, 2005). Two putative NTPDase enzymes are encoded on the $T$. brucei genome (Table 1), and assays using intact parasites demonstrate a cation-dependent, surface-located hydrolysis of ATP, GTP, CTP, UTP and ADP consistent with the presence of at least 1 NTPDase enzyme (de Souza Leite et al. 2007). Both predicted NTPDases contain N-terminal signal peptides, suggesting secretion by the parasite, but the localization, or indeed expression levels, of either putative enzyme are unknown. A recent study demonstrated inhibition of cell-surface NTPDase activity by ferrous iron and haem, although the mechanism of inhibition is not understood (Leite et al. 2009). The availability of successful RNAi systems in T. brucei could be utilized to elucidate the importance of these enzymes in virulence (Balana-Fouce and Reguera, 2007). 
While genome information is not available for a further species, $T$. rangeli, this parasite (capable of causing disease in humans and animals) also exhibits $\mathrm{Mg}^{2+}$-dependent cell-surface NTPDase activity against ATP, ADP and other NTPs, consistent with the presence of 1 or more NTPDases. In this species, hydrolysis of nucleotides is stimulated by a number of carbohydrates, leading to the hypothesis that NTPDase activity may have a role in adhesion to the intermediate insect host, as carbohydrates on insect salivary glands play a part in adhesion by Trypanosoma species (Fonseca et al. 2006), although there is no other evidence as yet for this theory. An atypical and non-pathogenic trypanosomatid, Crithidia deanei, is also observed to have surfacelocated NTPDase activity, with hydrolysis of ATP and other NTPs observed, but genome information is also unavailable for this species (dos Passos Lemos et al. 2002).

In Leishmania parasites, $\mathrm{Mg}^{2+}$-dependent cell surface-located NTPDase activity has been observed in 2 species responsible for cutaneous leishmaniasis, namely Leishmania tropica and Leishmania amazonensis (Meyer-Fernandes et al. 1997; Berredo-Pinho et al. 2001; Pinheiro et al. 2006). Again, however, it is not known which enzymes are responsible for this activity, although the nature of the activity is consistent with the presence of 1 or more NTPDases. While the genome sequence is not available for L. tropica or L. amazonensis, the presence of the 2 putative NTPDases on all 5 sequenced strains of Leishmania (Table 1) does suggest that L. tropica and L. amazonensis would also possess putative NTPDases on their genomes.

The localizations of the putative NTPDases are not known, but one early study demonstrated crossreaction on the surface of $L$. amazonensis with antibody to CD39 (human N'TPDase1), suggesting that the observed enzyme activity could be due to an NTPDase (Pinheiro et al. 2006). The presence of a predicted $\mathrm{N}$-terminal transmembrane domain in one NTPDase (Table 1) suggests that the protein could be anchored in the membrane on the cell surface, although equally it may be anchored in the membrane of an intracellular organelle such as the Golgi apparatus (as is the case for NTPDases in yeast (Berninsone et al.1994; Gao et al. 1999)). The second putative Leishmania NTPDase has a predicted N-terminal signal peptide, suggesting that the protein is secreted, and could be responsible for ecto-NTPDase activity.

While it is not confirmed that the observed enzyme activity is due to members of the NTPDase family, the characterization performed to date is broadly consistent with the presence of NTPDase(s). Interestingly, however, the enzymes identified in L. tropica and L. amazonensis cannot utilize $\mathrm{Ca}^{2+}$ instead of $\mathrm{Mg}^{2+}$, which is unusual for the NTPDase family (Meyer-Fernandes et al. 1997; Pinheiro et al. 2006).
In L. tropica parasites, surface-located hydrolysis of ATP and ADP as well as other NTPs has been observed, and hydrolysis of ATP and ADP is observed on the surface of L. amazonensis (Pinheiro et al. 2006). Similar to T. rangeli, carbohydrates stimulate the L. tropica ecto-NTPDase activity, although the mechanism and significance of this finding is unclear (Peres-Sampaio et al. 2001).

There is some evidence that this ecto-NTPDase activity may play a role in pathogenesis. Enzyme activity is higher in virulent strains than avirulent strains and is increased more than 10 -fold in the obligate intracellular amastigote stage (BerredoPinho et al. 2001; Pinheiro et al. 2006). The ectoATPase activity of L. amazonensis increases when parasites undergo heat shock (Peres-Sampaio et al. 2008), as occurs when the parasites leave the sand fly vector and are injected into the warmer mammalian host. It is important to note that this observed ectoenzyme activity has not been clearly demonstrated to be due to a member of the NTPDase family. However, treatment of parasites with anti-CD39 antibody reduces the interaction of the parasites with mouse peritoneal macrophages (Pinheiro et al. 2006), thus more directly suggesting a role for an NTPDase in pathogenesis. A recent study utilized chromium (III) adenosine 5'-triphosphate complex (CrATP) to inhibit ecto-ATPase activity in L. amazonensis, and found that CrATP pre-treatment of parasites reduced both attachment and entry into mouse peritoneal macrophages (Ennes-Vidal et al. 2011), also suggesting a role in virulence. However, it is important to note that CrATP also inhibited a $\mathrm{Mg}^{2+}$-independent ecto-ATPase activity on the parasite surface, and thus presumably is not a specific inhibitor of NTPDase activity. Leishmania can be genetically manipulated and systems exist both for generating defined molecular mutants (Cruz et al. 1991), and for introducing episomal DNA expressing Leishmania proteins, which may also be tagged, for example with GFP, to allow localization studies (Ha et al. 1996). Construction of genetically defined mutant strains where the putative NTPDases have been deleted, and localization of the proteins using epitope tagging would be of great benefit in determining the role the putative NTPDases play in the observed enzyme activity described by previous studies, as well as allowing a more direct examination of the contribution of the NTPDases to pathogenesis.

\section{Trichomonas vaginalis}

In a similar manner to the studies performed in Leishmania parasites, enzyme assays conducted using intact and disrupted $T$. vaginalis cells has demonstrated the presence of surface-located enzyme activity consistent with the presence of 1 or more ecto-NTPDases (de Aguiar Matos et al. 2001). This 
$\mathrm{Ca}^{2+}$ or $\mathrm{Mg}^{2+}$-dependent hydrolysis of ATP, ADP and other nucleotides can be increased by up to $90 \%$ by the addition of D-galactose (de Jesus et al. 2002), similar to the observed effects of carbohydrates on ecto-NTPDase activity in some trypanosomatids. This ecto-NTPDase activity is indirectly implicated in virulence, as fresh clinical isolates of $T$. vaginalis demonstrate higher surface NTPDase activity compared to a less virulent laboratory-adapted strain (de Jesus et al. 2002; Tasca et al. 2005).

Recent studies demonstrated an inhibition of ectoNTPDase activity when parasites were treated, for $24 \mathrm{~h}$, with the plant alkaloids lycorine and candimine which are toxic to T. vaginalis (Giordani et al. 2010). However, it is not clear if the toxicity of lycorine and candimine is directly related to the inhibition of ectoNTPDase activity. Interestingly, no effect of lycorine and candimine was seen on the expression levels of the 2 putative NTPDases examined in this study, suggesting that either the drugs act at a posttranscriptional level, or that the observed NTPDase activity which is inhibited by these drugs is due to 1 of 3 other putative NTPDases encoded on the $T$. vaginalis genome. Analysis of the effect of lycorine and candimine treatment on expression levels of these other 3 putative NTPDases would be useful. In contrast, treatment of freshly isolated parasites with steroids also inhibited ecto-NTPDase activity but this inhibition appeared to be due to inhibition at the level of mRNA transcription of the 2 NTPDases studied (Ruckert et al. 2010).

From these studies it is not clear precisely which putative NTPDases are responsible for the observed enzyme activity. Two of the 5 putative NTPDases possess predicted $\mathrm{N}$-terminal signal peptides, suggesting secretion by the parasite, and all 5 are predicted to have $\mathrm{C}$-terminal transmembrane domains, suggesting the proteins may be anchored in the extracellular membrane or in the membranes of organelles (Table 1). Use of RT-PCR to look at expression levels of all 5 genes, especially in response to compounds that demonstrate inhibitory effects on ecto-NTPDase activity, may help clarify which proteins are responsible for the extracellular NTPDase activity.

A related organism, Tritrichomonas foetus, a cause of abortion in cattle, also possesses $\mathrm{Mg}^{2+}$-dependent NTPDase activity. NTPs are hydrolysed, although no activity was detected against ADP, and activity is stimulated by D-mannose and D-galactose. However, as genome information is not available for this organism, it is not known if one or more NTPDases could be responsible for this observed activity (Jesus et al. 2002).

\section{Schistosoma mansoni}

The 2 NTPDases of $S$. mansoni have different localization patterns, suggesting functionally distinct roles. SmNTPDase1 is located on the surface, presumably anchored in the membrane by its predicted $\mathrm{N}$ - and C-terminal transmembrane domains, whereas SmNTPDase2 is secreted by the parasite (Vasconcelos et al. 1993; Levano-Garcia et al. 2007). While the role of each enzyme in parasite biology and disease pathogenesis is not yet known, it is intriguing that a new class of anti-schistosomal drugs, $\mathrm{N}$-alkylaminoalkanethiosulfuric acids, are known to partially inhibit tegumental $S$. mansoni NTPDase activity, indicating that the NTPDases may be suitable drug targets (Luiz Oliveira Penido et al. 2007). With the recent advent of RNAi techniques in S. mansoni (Bhardwaj et al. 2011) it would be informative if studies inhibiting either or both NTPDases were carried out, in order to assess the contribution of the enzymes to pathogenesis, and determine if they are indeed suitable drug targets.

\section{Fungi and other parasites}

As already discussed, the two NTPDases of $S$. cerevisisae are located in the Golgi and function in glycosylation and cell wall synthesis, and homologues of these proteins have been characterized in some other species of fungi. Evidence exists for NTPDase activity in other species of fungi in which the NTPDase homologues have not yet been characterized. Surface-located NTPDase activity stimulated by $\mathrm{Mg}^{2+}$ and exhibiting high rates of ATP, ITP, GTP, CTP and UTP but not ADP hydrolysis has been observed for $C$. neoformans (Junior et al. 2005). While the genome of $C$. neoformans encodes 2 putative NTPDases, these both appear to be homologues of the $S$. cerevisiae Golgi-located NTPDases (Fig. 2), and it is tempting to speculate that these NTPDases function in the Golgi apparatus of C. neoformans. However, in the absence of any localization studies it is possible that one of these putative NTPDases is responsible for the observed surface-located activity. Studies using specific antibodies to the $C$. neoformans NTPDases, or other molecular techniques, are crucial in determining the likely role of the NTPDases in C. neoformans. More recently, ecto-NTPDase activity has been observed in the pathogenic yeast $C$. parapsilosis (KifferMoreira et al. 2010). Again, however, it has not actually been shown whether an NTPDase is responsible for the observed activity. As already mentioned, in addition to GDA1 and YND1 homologues, the genome of $C$. parapsilosis does encode a third putative NTPDase that could certainly be surface-located, although it is closely related to the YND1 homologue (Fig. 2). Again, specific molecular studies to localize these proteins are key to identifying the function of NTPDases in C. parapsilosis. Finally, in the human pathogen Fonsecaea pedrosoi, surface-located ATPase activity stimulated by $\mathrm{Mg}^{2+}$ has been observed 
(Collopy-Junior et al. 2006). However, the genome sequence for this organism is not available and the protein(s) responsible for the enzyme activity are unknown, making it unclear whether an NTPDase is actually involved.

A number of other parasites have also been reported to display surface-located enzyme activity broadly consistent with the presence of NTPDase(s). These include Acanthamoeba, Enatamoeba histolytica and Giardia lamblia (Barros et al. 2000; Sissons et al. 2004; de Sa Pinheiro et al. 2008). However, as previously described in the literature (Sansom et al. $2008 b$ ), the genomes of these organisms encode no putative NTPDases, and thus will not be discussed in detail here, as the focus of this review is the NTPDase family of proteins. The amoebae Balamuthia mandrillaris has also been reported to have surfacelocated ATPase activity (Matin and Khan, 2008), but genome information is unavailable and it is impossible to determine whether an NTPDase is involved.

POTENTIAL FUNCTIONS OF NTPDASES IN PATHOGENIC PARASITES

In humans NTPDases appear to play diverse roles including purine salvage, control of blood clotting and regulation of the immune and inflammatory response (Deaglio and Robson, 2011). In yeast NTPDases function in the Golgi playing crucial roles in glycosylation (Berninsone et al. 1994; Gao et al. 1999), whereas in L. pneumophila secreted NTPDases contribute to the virulence of the bacteria in the mammalian host (Sansom et al. 2007, 2008a). To date, the data in parasites suggest potential roles for NTPDases in both parasite biology and disease pathogenesis, and indeed previous reviews of the literature have also suggested a diverse range of functions for NTPDase activity in parasites (MeyerFernandes, 2002; Meyer-Fernandes et al. 2010; Paletta-Silva and Meyer-Fernandes, 2012). The mechanisms by which NTPDases may influence such a diverse array of cellular functions are now discussed, including the evidence for such functions in parasites.

\section{Vascular haemostasis}

Purinergic signalling is key in modulating the platelet aggregation response. Three purinergic receptor types, namely $\mathrm{P} 2 \mathrm{X}_{1}, \mathrm{P} 2 \mathrm{Y}_{1}$ and $\mathrm{P} 2 \mathrm{Y}_{12}$, are present on platelets and are activated either by ATP $\left(\mathrm{P}_{2} \mathrm{X}_{1}\right)$ or ADP (P2Y). ATP activation of $\mathrm{P}_{2} \mathrm{X}_{1}$ specifically contributes to platelet activation induced by low concentrations of collagen and may play a role in priming of the $\mathrm{P}_{2} \mathrm{Y}_{1}$ receptor. ADP-induced aggregation results from activation of both the $\mathrm{P}_{2} \mathrm{Y}_{1}$ and $\mathrm{P} 2 \mathrm{Y}_{12}$ receptors (Gachet, 2006). Therefore, hydrolysis of extracellular ATP and ADP by human NTPDases affects the level of platelet activation and aggregation. Human NTPDase2 predominantly hydrolyses ATP with little ADPase activity, and thus stimulates platelet aggregation. In contrast CD39 (human NTPDase1) rapidly hydrolyses ADP and limits the platelet aggregation response (Atkinson et al. 2006). The importance of these enzymes in vascular homeostasis is evident from the bleeding phenotype displayed by $c d 39$ null mice (Enjyoji et al. 1999). It is therefore reasonable to suppose that secreted and ecto-NTPDases of parasites, in particular in those parasites with life-cycle stages in the mammalian bloodstream, may be able to modulate platelet activation to facilitate parasite survival.

Schistosoma mansoni reaches the bloodstream approximately 2 days after host infection, and cutaneous infection in mice reveals that a brief thrombocytopenia coincides with parasites entering the blood. Platelets are able to attach to $S$. mansoni larvae in vitro, and the observed thrombocytopenia is likely to reflect an activation and attachment of platelets to larvae as a mechanism of host defence. Within a few days of infection, however, platelet numbers return to a level similar to that seen in uninfected control animals, despite the continued presence of larvae in the bloodstream, suggesting that the parasites resist this method of host defence (Stanley et al. 2003). Both SmNTPDase1 and SmNTPDase2 are expressed by larvae, and induction of these enzymes in response to platelet aggregation and subsequent hydrolysis of ADP by these NTPDases could be one explanation for the development of resistance to platelet aggregation, as has been suggested previously (Sansom et al. 2008b; Vasconcelos et al. 1993).

Both T. cruzi and T. brucei have bloodstream lifecycle stages and, in particular, $T$. brucei remains extracellular and replicates within the bloodstream. Thus, as suggested previously (Sansom et al. 2008b), it would seem likely that inhibition of platelet aggregation would be of benefit to the parasites. However, both T. brucei and T. cruzi are reported to cause platelet aggregation with resultant thrombocytopenia ('Tanowitz et al. 1990; Okenu et al. 1999) and platelet recruitment is known to remove opsonised T. cruzi from the circulation (Umekita et al. 1994). Although the NTPDase of T. cruzi preferentially hydrolyses ATP, thus releasing ADP that would activate platelets by binding $\mathrm{P} 2 \mathrm{Y}$ receptors, ADP hydrolysis by TcNTPDase is still efficient (Santos et al. 2009), which would suggest a role in inhibition of platelet aggregation. Furthermore the observed ecto-enzyme activity for T. brucei demonstrates efficient hydrolysis of both ATP and ADP (de Souza Leite et al. 2007). Further study of the NTPDases of T. cruzi and T. brucei is needed to elucidate the function of these enzymes during the bloodstream stage of the life cycle. It may be that in the absence of these enzymes, the platelet aggregation response is significantly worsened. 
Plasmodium falciparum also has a crucial bloodstream phase in its life cycle. Recently it was clearly demonstrated that platelets bind to Plasmodiuminfected erythrocytes and kill the parasite, and this effect was abrogated in the presence of platelet inhibitors including, importantly, an ADPase (McMorran et al. 2009). Thus the presence of a putative NTPDase gene in the genome of $P$. falciparum is clearly of interest. The presence of the two predicted transmembrane domains suggests that the enzyme could be anchored on the parasite surface, in a manner similar to the anchoring of CD39 on the surface of mammalian cells (Marcus et al. 1997). In this context the closer evolutionary relationship of PfNTPDase to mammalian surfacelocated NTPDases such as CD39, rather than to the other apicomplexan NTPDases (Fig. 2) is especially intriguing. Determining the localization of the protein, as well as the substrate preference of the enzyme, in particular with regard to the ATP:ADP ratio, may help clarify the importance of the $P$. falciparum NTPDase in defence against platelet aggregation.

\section{Inflammation and immune response}

Nucleotides such as ATP are released from dead and damaged cells, and as extracellular concentrations rise become important 'danger signals' for the mammalian host (Bours et al. 2006; Burnstock, 2007). ATP activates both $\mathrm{P} 2 \mathrm{X}$ and $\mathrm{P} 2 \mathrm{Y}$ receptors, resulting in the release of pro-inflammatory cytokines (Pizzirani et al. 2007). Importantly, CD39 (human NTPDase1) inhibits ATP-stimulated cytokine release from mammalian cells (Levesque et al. 2010; Kukulski et al. 2011), and it seems reasonable to hypothesize that surface-located or secreted NTPDases of parasites could act in a similar manner, hydrolysing ATP and suppressing the inflammatory and immune response (Sansom et al. 2008b). CD39 is also expressed on the surface of regulatory $\mathrm{T}$ cells, and the expression of CD39 on these cells has been linked to decreased dendritic cell activation (Borsellino et al. 2007; Deaglio et al. 2007). The $\mathrm{P} 2 \mathrm{Y}$ receptors are also activated by non-adenine nucleotides, such as UTP and UDP (Burnstock, 2007). For example, stimulation of cells with UTP results in expression and release of the pro-inflammatory cytokine IL-6 (Douillet et al. 2006) and in monocytic cells UDP activates $\mathrm{P}_{2} \mathrm{Y}_{6}$ receptors to stimulate production and release of IL- 8 and TNF- $\alpha$ (Cox et al. 2005). As already reviewed here, a large number of parasites have ecto-enzyme activity (although not always proven to be a result of NTPDase expression) against purine and pyrimidine nucleotides such as GTP, UTP and CTP, and in general hydrolysis occurs with similar efficiency with respect to ATP and ADP. Therefore, hydrolysis of a number of nucleotides, not just ATP, by surface-located or secreted NTPDases of parasites could suppress the host immune response.

Two recent studies directly examined $\mathrm{P} 2$ receptor expression and activation in the presence of L. amazonensis infection. $\mathrm{P}_{2} \mathrm{X}_{7}$ receptors, known to be important in the killing of certain intracellular bacteria (Sansom et al. 2008b), were upregulated in murine macrophages infected with L. amazonensis and were also more responsive to extracellular ATP. Cells treated with extracellular ATP were able to inhibit parasite growth, in a manner dependent on $\mathrm{P}_{2} \mathrm{X}_{7}$ receptor expression (Chaves et al. 2009). A second study examined the effect of uridine nucleotides in L. amazonensis macrophage infection, and found that UTP treatment resulted in nitric oxide and peroxide production in macrophages infected with L. amazonensis. Infected macrophages, but not uninfected ones, also underwent apoptosis when stimulated by UTP or UDP. P2 $\mathrm{Y}_{2}$ and $\mathrm{P} 2 \mathrm{Y}_{4}$ receptors, which bind UTP, had increased levels of expression in macrophages following L. amazonensis infection (Marques-da-Silva et al. 2011). Prevention of apoptosis is one method by which L. amazonensis is thought to enhance its survival inside the host (Heussler et al. 2001), and expression of cell surface or secreted NTPDases to degrade nucleotides such as ATP and UTP could be one mechanism to achieve apoptosis prevention. This link has not been proven, however, and it is important to note that Leishmania parasites are intracellular, so the manner in which the NTPDases would be able to degrade the extracellular nucleotides needs elucidation.

Generation of adenosine is another process by which parasites could suppress the inflammatory response. In the case of regulatory $\mathrm{T}$ cells immune suppression results not just from hydrolysis of ATP (to AMP) by CD39, but through simultaneous expression of CD73, an ecto-5'-nucleotidase that hydrolyses AMP to produce adenosine, a potent antiinflammatory molecule. Adenosine acts via P1 receptors (specifically the $\mathrm{A} 2 \mathrm{~A}$ subclass) and mediates immune suppression through a number of effects, including repression of pro-inflammatory cytokine expression and inhibition of effector $\mathrm{T}$ cell activation (Deaglio et al. 2007).

Certain parasites display ecto-5'-nucleotidase activity, including $T$. vaginalis, $S$. mansoni and Leishmania and Trypanosoma species. Apicomplexan parasites, however, do not appear to display ecto-5'nucleotidase activity (Sansom et al. 2008b). As suggested previously by other authors (Bhardwaj and Skelly, 2009), for those parasites possessing both secreted or surface-located NTPDase, and ecto-5'nucleotidase activity, generation of adenosine may play a role in suppressing the immune response of the host. Some evidence for the importance of adenosine in the immune response of the host is provided by a study examining the effect of adenosine on the ability of different Leishmania species to infect C57BL/6 
mice (de Almeida Marques-da-Silva et al. 2008). This mouse strain is resistant to 2 species, L. major and L. braziliensis, but susceptible to L. amazonensis. Higher levels of hydrolysis of ATP, ADP and AMP were observed for L. amazonensis, which the authors speculate may be responsible for the increased virulence of this species, although this link has not been definitively proven. Addition of adenosine at the time of infection increased lesion size, whereas blockage of $\mathrm{A} 2 \mathrm{~A}$ receptors decreased the size of lesions. Most recently, the inflammatory response of mice to strains of L. amazonensis was found to be different depending on the clinical source of the strain used (Souza et al. 2011). The ecto-NTPDase activity levels differed between the parasite strains, although other biochemical differences between the strains were also observed and it is not possible to definitively conclude that the ecto-NTPDase activity levels were directly related to the observed differences in inflammation. Further work examining defined mutants lacking NTPDases would be useful in establishing the true role of NTPDases in establishment of Leishmania infection.

\section{Purine salvage}

It is presumed that NTPDases in mammals, in concert with ecto-5'-nucleotidase and nucleoside transporters, play a role in scavenging purines (Robson et al. 2006). All the parasites reviewed here (with the exception of yeast) are purine auxotrophs and, as suggested previously, ecto-NTPDase activity may be involved in purine salvage pathways (Sansom et al. 2008b). As already discussed, ecto-5'-nucleotidase activity is present in all parasites except the apicomplexan parasites, allowing the production of adenosine which may then be taken up by the parasites. In the case of the apicomplexa, the lack of ecto-5'nucleotidase activity indicates that ecto-NTPDases do not play an independent role in purine salvage, but does not preclude the possibility that the parasites could utilize host enzymes for some steps in purine salvage. It does suggest, however, that at least in apicomplexan parasites, the role of ecto-NTPDases is more complex than simply the scavenging of purines.

\section{Nucleotide sugar transport}

To date, studies of NTPDases in parasites have focused on the role of secreted and surface-located NTPDases. It is worth noting, however, that for the majority of putative NTPDases encoded on parasite genomes the localization is unknown (Table 1). While a number do contain putative N-terminal signal peptides, suggesting secretion from the parasite, a number of others contain predicted transmembrane domains. While these could play a role in anchoring the protein in the membrane on the cell surface, it is equally possible that these proteins are

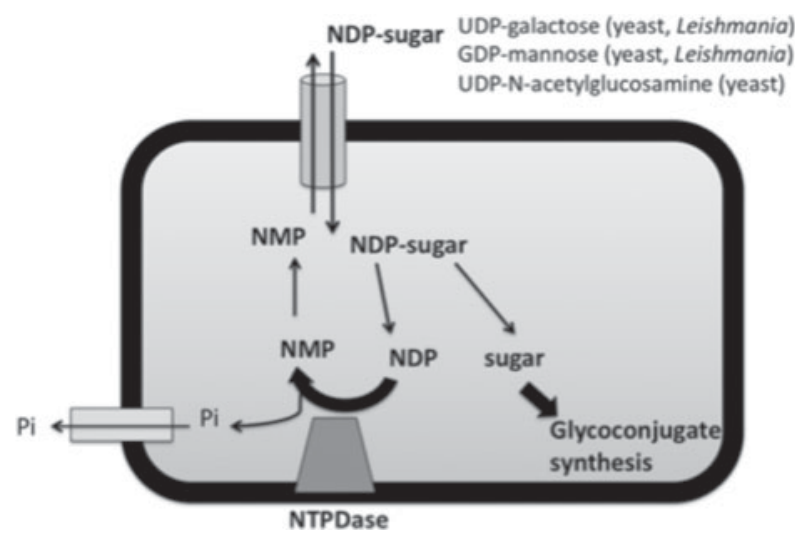

Fig. 3. Schematic of nucleotide-sugar transport into the Golgi of yeast and Leishmania and Trichomonas vaginalis parasites. Different transporters exist for the different nucleotide sugars. The function of an NTPDase in the process is known for some species of yeast, but only postulated for Leishmania and T. vaginalis. In parasites inorganic phosphate may be also incorporated into structures such as lipophosphoglycan, but not all phosphate generated is required for this process, and an NTPDase may still be required. Various enzymes (not shown here) are required to remove the sugar from the nucleotide and incorporate it into the glycoconjugate molecules. Figure adapted from Hirschberg et al. (1998).

located in organelles such as the Golgi, with the active site located in the lumen of the organelle (as is the case for human NTPDase4 and NTPDase7 (Zimmermann et al. 2000). As discussed earlier, in yeast, all N'TPDases characterized to date function in the Golgi and deletion results in defective glycosylation. These defects occur because NTPDases are required for nucleotide sugar transport into the Golgi. For example, UDP-galactose is exchanged for UMP, and the galactose molecule used in glycosylation. The Golgi-located NTPDases play crucial roles in regenerating nucleotide monophosphates from nucleotide diphosphates, to allow nucleotide sugar transport to continue efficiently (Figure 3) (Berninsone et al. 1994; Gao et al. 1999).

Glycoconjugates of a number of parasites are thought to have key functions in the host-parasite interaction. Depending on the parasite species, important glycoconjugates include lipophosphoglycans (LPG), N-glycans and O-glycans (GuhaNiyogi et al. 2011). The parasites in which the localization of the putative NTPDases is unknown include Trypanosoma, Leishmania and T. vaginalis (Table 1). Of these, both Leishmania and T. vaginalis possess putative NTPDases that contain no signal peptide but do contain predicted transmembrane domains, and these proteins could be present in intracellular organelles. Lending some support to this hypothesis, the Leishmania NTPDases containing predicted transmembrane domains have a closer relationship to the Golgi-located GDA1 of C. albicans than the Leishmania NTPDases 
containing signal peptides for secretion do (Fig. 2). The $T$. vaginalis NTPDases are also more closely related to the intracellular organelle-located human NTPDases (NTPDase4 and NTPDase7) than to the cell surface-located NTPDases (Fig. 2). For both parasite species glycoconjugates are important in virulence. In L. major, for example, LPG plays an important role in the ability of the promastigote form of the parasite to resist complement-mediated lysis and oxidative stress, and mutants lacking LPG are significantly delayed in their ability to cause lesions in susceptible mouse strains (Spath et al. 2000). $T$. vaginalis parasites require $\mathrm{LPG}$ for efficient adherence to host cells, and mutants lacking LPG are also less cytotoxic (Bastida-Corcuera et al. 2005). It may be that either or both parasites possess organelle-located NTPDases important in the synthesis of glycoconjugate molecules.

\section{CONCLUSIONS}

The diverse roles played by N'TPDases in mammals and yeast suggests that a number of functions could exist for this family of enzymes in pathogenic parasites, particularly in the interaction with the host. There is substantial evidence at the genome level for the presence of NTPDases in a number of pathogenic parasites, but varying information in regards to the biological role of these NTPDases. Nonetheless, there is a large body of evidence, although principally indirect, suggesting the importance of these enzymes in parasite biology and pathogenesis. Future work utilizing genetic techniques to more directly address the role(s) of NTPDases would be highly useful in elucidating the function of NTPDases and their suitability as drug targets.

\section{ACKNOWLEDGMENTS}

An Australian National Health and Medical Research Council (NH\&MRC) Australian Biomedical Fellowship (\#567048) supports F.M. Sansom. The support of Professor Malcolm McConville at The University of Melbourne is also gratefully acknowledged.

\section{REFERENCES}

Abeijon, C., Yanagisawa, K., Mandon, E. C., Hausler, A., Moremen, K., Hirschberg, C. B. and Robbins, P.W. (1993). Guanosine diphosphatase is required for protein and sphingolipid glycosylation in the Golgi lumen of Saccharomyces cerevisiae. The fournal of Cell Biology 122, 307-323.

Asai, T., Howe, D. K., Nakajima, K., Nozaki, T., Takeuchi, T. and Sibley, L. D. (1998). Neospora caninum: tachyzoites express a potent type-I nucleoside triphosphate hydrolase. Experimental Parasitology 90, 277-285. Asai, T., Miura, S., Sibley, L. D., Okabayashi, H. and Takeuchi, T. (1995). Biochemical and molecular characterization of nucleoside triphosphate hydrolase isozymes from the parasitic protozoan Toxoplasma gondii. The Yournal of Biological Chemistry 270, 11391-11397.

Atkinson, B., Dwyer, K., Enjyoji, K. and Robson, S. C. (2006). Ectonucleotidases of the CD39/NTPDase family modulate platelet activation and thrombus formation: Potential as therapeutic targets. Blood Cells, Molecules, and Diseases 36, 217-222.
Balana-Fouce, R. and Reguera, R. M. (2007). RNA interference in Trypanosoma brucei: a high-throughput engine for functional genomics in trypanosomatids? Trends in Parasitology 23, 348-351. doi: 10.1016/j. pt.2007.06.008.

Barros, F.S., De Menezes, L.F., Pinheiro, A. A., Silva, E. F., Lopes, A. H., De Souza, W. and Meyer-Fernandes, J. R. (2000). Ectonucleotide diphosphohydrolase activities in Entamoeba histolytica. Archives of Biochemistry and Biophysics 375, 304-314.

Bastida-Corcuera, F. D., Okumura, C.Y., Colocoussi, A. and Johnson, P. J. (2005). Trichomonas vaginalis lipophosphoglycan mutants have reduced adherence and cytotoxicity to human ectocervical cells. Eukaryotic Cell, 4(11), 1951-1958. doi: 10.1128/EC.4.11.19511958.2005.

Bermudes, D., Peck, K. R., Afifi, M. A., Beckers, C. J. and Joiner, K. A. (1994). Tandemly repeated genes encode nucleoside triphosphate hydrolase isoforms secreted into the parasitophorous vacuole of Toxoplasma gondii. The Fournal of Biological Chemistry 269, 29252-29260.

Bernardes, C. F., Meyer-Fernandes, J. R., Saad-Nehme, J., VannierSantos, M. A., Peres-Sampaio, C. E. and Vercesi, A. E. (2000). Effects of 4,4'-diisothyocyanatostilbene-2,2'-disulfonic acid on Trypanosoma cruzi proliferation and $\mathrm{Ca}(2+)$ homeostasis. The International Fournal of Biochemistry and Cell Biology 32, 519-527.

Berninsone, P., Miret, J. J. and Hirschberg, C. B. (1994). The Golgi guanosine diphosphatase is required for transport of GDP-mannose into the lumen of Saccharomyces cerevisiae Golgi vesicles. The Fournal of Biological Chemistry 269, 207-211.

Berredo-Pinho, M., Peres-Sampaio, C. E., Chrispim, P. P., BelmontFirpo, R., Lemos, A.P., Martiny, A., Vannier-Santos, M. A. and Meyer-Fernandes, J.R. (2001). A Mg-dependent ecto-ATPase in Leishmania amazonensis and its possible role in adenosine acquisition and virulence. Archives of Biochemistry and Biophysics 391, 16-24. doi:10.1006/ abbi.2001.2384S0003-9861(01)92384-7 [pii].

Berriman, M., Ghedin, E., Hertz-Fowler, C., Blandin, G., Renauld, H., Bartholomeu, D. C., Lennard, N. J., Caler, E., Hamlin, N. E., Haas, B., Bohme, U., Hannick, L., Aslett, M. A., Shallom, J., Marcello, L., Hou, L., Wickstead, B., Alsmark, U. C., Arrowsmith, C., Atkin, R. J., Barron, A. J., Bringaud, F., Brooks, K., Carrington, M., Cherevach, I., Chillingworth, T. J., Churcher, C., Clark, L. N., Corton, C. H., Cronin, A., Davies, R. M., Doggett, J., Djikeng, A., Feldblyum, T., Field, M. C., Fraser, A., Goodhead, I., Hance, Z., Harper, D., Harris, B. R., Hauser, H., Hostetler, J., Ivens, A., Jagels, K., Johnson, D., Johnson, J., Jones, K., Kerhornou, A. X., Koo, H., Larke, N., Landfear, S., Larkin, C., Leech, V., Line, A., Lord, A., Macleod, A., Mooney, P. J., Moule, S., Martin, D. M., Morgan, G.W., Mungall, K., Norbertczak, H., Ormond, D., Pai, G., Peacock, C.S., Peterson, J., Quail, M. A., Rabbinowitsch, E., Rajandream, M. A., Reitter, C., Salzberg, S. L., Sanders, M., Schobel, S., Sharp, S., Simmonds, M., Simpson, A. J., Tallon, L., Turner, C. M., Tait, A., Tivey, A. R., Van Aken, S., Walker, D., Wanless, D., Wang, S., White, B., White, O., Whitehead, S., Woodward, J., Wortman, J., Adams, M. D., Embley, T.M., Gull, K., Ullu, E., Barry, J.D., Fairlamb, A. H., Opperdoes, F., Barrell, B. G., Donelson, J. E., Hall, N., Fraser, C. M., Melville, S. E. and El-Sayed, N. M. (2005). The genome of the African trypanosome Trypanosoma brucei. Science 309, 416-422. doi: 10.1126/ science. 1112642 .

Bhardwaj, R., Krautz-Peterson, G. and Skelly, P. J. (2011). Using RNA interference in Schistosoma mansoni. Methods in Molecular Biology 764, 223-239. doi: 10.1007/978-1-61779-188-8_15.

Bhardwaj, R. and Skelly, P. J. (2009). Purinergic signaling and immune modulation at the schistosome surface? Trends in Parasitology 25, 256-260. doi: 10.1016/j.pt.2009.03.004.

Bisaggio, D.F., Peres-Sampaio, C. E., Meyer-Fernandes, J. R. and Souto-Padron, T. (2003). Ecto-ATPase activity on the surface of Trypanosoma cruzi and its possible role in the parasite-host cell interaction. Parasitology Research 91, 273-282. doi: 10.1007/s00436-003-0965-8.

Borsellino, G., Kleinewietfeld, M., Di Mitri, D., Sternjak, A., Diamantini, A., Giometto, R., Hopner, S., Centonze, D., Bernardi, G., Dell'Acqua, M. L., Rossini, P. M., Battistini, L., Rotzschke, O. and Falk, K. (2007). Expression of ectonucleotidase CD39 by Foxp3 + Treg cells: hydrolysis of extracellular ATP and immune suppression. Blood 110, 1225-1232.

Bours, M. J., Swennen, E. L., Di Virgilio, F., Cronstein, B. N. and Dagnelie, P.C. (2006). Adenosine 5'-triphosphate and adenosine as endogenous signaling molecules in immunity and inflammation. Pharmacology and Therapeutics, 112, 358-404.

Burnstock, G. (1972). Purinergic nerves. Pharmacological Reviews 24, 509-581. 
Burnstock, G. (2007). Purine and pyrimidine receptors. Cellular and Molecular Life sciences 64, 1471-1483.

Butler, G., Rasmussen, M.D., Lin, M.F., Santos, M. A., Sakthikumar, S., Munro, C. A., Rheinbay, E., Grabherr, M., Forche, A., Reedy, J. L., Agrafioti, I., Arnaud, M. B., Bates, S., Brown, A. J., Brunke, S., Costanzo, M. C., Fitzpatrick, D. A., de Groot, P. W., Harris, D., Hoyer, L.L., Hube, B., Klis, F. M., Kodira, C., Lennard, N., Logue, M. E., Martin, R., Neiman, A. M., Nikolaou, E., Quail, M.A., Quinn, J., Santos, M.C., Schmitzberger, F.F., Sherlock, G., Shah, P., Silverstein, K. A., Skrzypek, M. S., Soll, D., Staggs, R., Stansfield, I., Stumpf, M. P., Sudbery, P. E., Srikantha, T., Zeng, Q., Berman, J., Berriman, M., Heitman, J., Gow, N. A., Lorenz, M. C., Birren, B. W., Kellis, M. and Cuomo, C. A. (2009). Evolution of pathogenicity and sexual reproduction in eight Candida genomes. Nature, London 459, 657-662. doi: 10.1038/ nature 08064

Carlton, J. M., Hirt, R.P., Silva, J. C., Delcher, A. L., Schatz, M., Zhao, Q., Wortman, J. R., Bidwell, S. L., Alsmark, U. C., Besteiro, S., Sicheritz-Ponten, T., Noel, C. J., Dacks, J. B., Foster, P. G., Simillion, C., Van de Peer, Y., Miranda-Saavedra, D., Barton, G. J., Westrop, G. D., Muller, S., Dessi, D., Fiori, P. L., Ren, Q., Paulsen, I., Zhang, H., Bastida-Corcuera, F.D., Simoes-Barbosa, A., Brown, M. T., Hayes, R.D., Mukherjee, M., Okumura, C. Y., Schneider, R., Smith, A. J., Vanacova, S., Villalvazo, M., Haas, B. J., Pertea, M., Feldblyum, T.V., Utterback, T. R., Shu, C. L., Osoegawa, K., de Jong, P. J., Hrdy, I., Horvathova, L., Zubacova, Z., Dolezal, P., Malik, S. B., Logsdon, J. M. Jr., Henze, K., Gupta, A., Wang, C. C., Dunne, R. L., Upcroft, J. A., Upcroft, P., White, O., Salzberg, S. L., Tang, P., Chiu, C. H., Lee, Y.S., Embley, T.M., Coombs, G. H., Mottram, J. C., Tachezy, J., Fraser-Liggett, C. M. and Johnson, P. J. (2007). Draft genome sequence of the sexually transmitted pathogen Trichomonas vaginalis. Science $\mathbf{3 1 5}, \mathbf{2 0 7 - 2 1 2}$

Chaves, S.P., Torres-Santos, E. C., Marques, C., Figliuolo, V. R., Persechini, P. M., Coutinho-Silva, R. and Rossi-Bergmann, B. (2009). Modulation of $\mathrm{P} 2 \mathrm{X}(7)$ purinergic receptor in macrophages by Leishmania amazonensis and its role in parasite elimination. Microbes and Infection/Institut Pasteur 11, 842-849. doi: 10.1016/j.micinf.2009.05.001. Chien, M., Morozova, I., Shi, S., Sheng, H., Chen, J., Gomez, S. M., Asamani, G., Hill, K., Nuara, J., Feder, M., Rineer, J., Greenberg, J. J., Steshenko, V., Park, S. H., Zhao, B., Teplitskaya, E., Edwards, J. R., Pampou, S., Georghiou, A., Chou, I. C., Iannuccilli, W., Ulz, M. E., Kim, D. H., Geringer-Sameth, A., Goldsberry, C., Morozov, P., Fischer, S. G., Segal, G., Qu, X., Rzhetsky, A., Zhang, P., Cayanis, E., De Jong, P. J., Ju, J., Kalachikov, S., Shuman, H. A. and Russo, J. J. (2004). The genomic sequence of the accidental pathogen Legionella pneumophila. Science 305, 1966-1968.

Collopy-Junior, I., Kneipp, L.F., da Silva, F.C., Rodrigues, M. L., Alviano, C. S. and Meyer-Fernandes, J. R. (2006). Characterization of an ecto-ATPase activity in Fonsecaea pedrosoi. Archives of Microbiology 185, 355-362.

Cox, M. A., Gomes, B., Palmer, K., Du, K., Wiekowski, M., Wilburn, B., Petro, M., Chou, C. C., Desquitado, C., Schwarz, M., Lunn, C., Lundell, D., Narula, S. K., Zavodny, P. J. and Jenh, C. H. (2005). The pyrimidinergic P2Y6 receptor mediates a novel release of proinflammatory cytokines and chemokines in monocytic cells stimulated with UDP. Biochemical and Biophysical Research Communications 330, 467-473

Cruz, A., Coburn, C. M. and Beverley, S. M. (1991). Double targeted gene replacement for creating null mutants. Proceedings of the National Academy of Sciences, USA 88, 7170-7174.

de Aguiar Matos, J. A., Borges, F.P., Tasca, T., Bogo, M. R., De Carli, G. A., da Graca Fauth, M., Dias, R. D. and Bonan, C. D. (2001). Characterisation of an ATP diphosphohydrolase (Apyrase, EC 3.6.1.5) activity in Trichomonas vaginalis. International fournal for Parasitology 31, $770-775$

de Almeida Marques-da-Silva, E., de Oliveira, J.C., Figueiredo, A. B., de Souza Lima Junior, D., Carneiro, C. M., Rangel Fietto, J. L. and Crocco Afonso, L. C. (2008). Extracellular nucleotide metabolism in Leishmania: influence of adenosine in the establishment of infection. Microbes and Infection/Institut Pasteur 10 850-857. doi: 10.1016/j.micinf.2008.04.016.

de Jesus, J. B., de Sa Pinheiro, A. A., Lopes, A.H. and MeyerFernandes, J. R. (2002). An ectonucleotide ATP-diphosphohydrolase activity in Trichomonas vaginalis stimulated by galactose and its possible role in virulence. Zeitschrift für Naturforschung C 57, 890-896.

de Sa Pinheiro, A. A., Cosentino-Gomes, D., Lanfredi-Rangel, A., Ferraro, R. B., De Souza, W. and Meyer-Fernandes, J. R. (2008).
Giardia lamblia: biochemical characterization of an ecto-ATPase activity. Experimental Parasitology 119, 279-284. doi: S0014-4894(08)00055-6 [pii] 10.1016/j.exppara.2008.02.006

de Souza Leite, M., Thomaz, R., Fonseca, F. V., Panizzutti, R., Vercesi, A. E. and Meyer-Fernandes, J. R. (2007). Trypanosoma brucei brucei: Biochemical characterization of ecto-nucleoside triphosphate diphosphohydrolase activities. Experimental Parasitology 115, 315-323.

Deaglio, S., Dwyer, K. M., Gao, W., Friedman, D., Usheva, A. Erat, A., Chen, J. F., Enjyoji, K., Linden, J., Oukka, M., Kuchroo, V. K., Strom, T. B. and Robson, S. C. (2007). Adenosine generation catalyzed by CD39 and CD73 expressed on regulatory $\mathrm{T}$ cells mediates immune suppression. The fournal of Experimental Medicine 204, 1257-1265.

Deaglio, S. and Robson, S. C. (2011). Ectonucleotidases as regulators of purinergic signaling in thrombosis, inflammation, and immunity. Advances in Pharmacology 61, 301-332. doi: 10.1016/B978-0-12-385526-8.00010-2.

dos Passos Lemos, A., de Sa Pinheiro, A. A., de Berredo-Pinho, M. Fonseca de Souza, L., Motta, C. M., de Souza, W. and MeyerFernandes, R. (2002). Ectonucleotide diphosphohydrolase activity in Crithidia deanei. Parasitology Research 88, 905-911. doi: 10.1007/s00436002-0671-y

Douillet, C. D., Robinson, W. P. 3rd, Milano, P. M., Boucher, R. C. and Rich, P. B. (2006). Nucleotides induce IL-6 release from human airway epithelia via P2Y2 and p38 MAPK-dependent pathways. American fournal of Physiology. Lung Cellular and Molecular Physiology 291, L734-746.

Downing, T., Imamura, H., Decuypere, S., Clark, T. G., Coombs, G. H., Cotton, J. A., Hilley, J. D., de Doncker, S., Maes, I., Mottram, J. C., Quail, M. A., Rijal, S., Sanders, M., Schonian, G., Stark, O., Sundar, S., Vanaerschot, M., Hertz-Fowler, C., Dujardin, J. C. and Berriman, M. (2011). Whole genome sequencing of multiple Leishmania donovani clinical isolates provides insights into population structure and mechanisms of drug resistance. Genome Research 21, 2143-2156. doi: 10.1101/gr.123430.111.

Dwyer, K. M., Robson, S.C., Nandurkar, H.H., Campbell, D. J., Gock, H., Murray-Segal, L. J., Fisicaro, N., Mysore, T. B., Kaczmarek, E., Cowan, P. J. and d'Apice, A. J. (2004). Thromboregulatory manifestations in human CD39 transgenic mice and the implications for thrombotic disease and transplantation. The fournal of Clinical Investigation 113, 1440-1446.

Enjyoji, K., Sevigny, J., Lin, Y., Frenette, P.S., Christie, P.D., Esch, J. S. 2nd, Imai, M., Edelberg, J. M., Rayburn, H., Lech, M., Beeler, D. L., Csizmadia, E., Wagner, D. D., Robson, S. C. and Rosenberg, R. D. (1999). Targeted disruption of cd39/ATP diphosphohydrolase results in disordered hemostasis and thromboregulation. Nature Medicine 5, 1010-1017.

Ennes-Vidal, V., Castro, R. O., Britto, C., Barrabin, H., D’AvilaLevy, C. M. and Moreira, O.C. (2011). CrATP interferes in the promastigote-macrophage interaction in Leishmania amazonensis infection. Parasitology 138, 960-968. doi: 10.1017/S0031182011000710.

Fietto, J. L., DeMarco, R., Nascimento, I. P., Castro, I. M. Carvalho, T.M., de Souza, W., Bahia, M. T., Alves, M. J. and Verjovski-Almeida, S. (2004). Characterization and immunolocalization of an NTP diphosphohydrolase of Trypanosoma cruzi. Biochemical and Biophysical Research Communications 316, 454-460.

Fonseca, F. V., Fonseca de Souza, A. L., Mariano, A. C., Entringer, P. F., Gondim, K. C. and Meyer-Fernandes, J. R. (2006) Trypanosoma rangeli: characterization of a Mg-dependent ecto ATPdiphosphohydrolase activity. Experimental Parasitology 112, 76-84.

Gachet, C. (2006). Regulation of platelet functions by P2 receptors. Annual Review of Pharmacology and Toxicology 46, 277-300.

Gao, X. D., Kaigorodov, V. and Jigami, Y. (1999). YND1, a homologue of GDA1, encodes membrane-bound apyrase required for Golgi N- and Oglycosylation in Saccharomyces cerevisiae. The Fournal of Biological Chemistry 274, 21450-21456.

Gardner, M. J., Hall, N., Fung, E., White, O., Berriman, M., Hyman, R. W., Carlton, J. M., Pain, A., Nelson, K. E., Bowman, S. Paulsen, I. T., James, K., Eisen, J. A., Rutherford, K., Salzberg, S. L., Craig, A., Kyes, S., Chan, M.S., Nene, V., Shallom, S. J., Suh, B., Peterson, J., Angiuoli, S., Pertea, M., Allen, J., Selengut, J., Haft, D. Mather, M. W., Vaidya, A. B., Martin, D. M., Fairlamb, A. H., Fraunholz, M. J., Roos, D.S., Ralph, S. A., McFadden, G. I., Cummings, L. M., Subramanian, G. M., Mungall, C., Venter, J. C., Carucci, D. J., Hoffman, S. L., Newbold, C., Davis, R. W., Fraser, C. M. and Barrell, B. (2002). Genome sequence of the human malaria parasite Plasmodium falciparum. Nature, London 419, 498-511.

Giordani, R. B., Weizenmann, M., Rosemberg, D. B., De Carli, G. A., Bogo, M. R., Zuanazzi, J. A. and Tasca, T. (2010). Trichomonas vaginalis nucleoside triphosphate diphosphohydrolase and ecto-5'-nucleotidase 
activities are inhibited by lycorine and candimine. Parasitology International 59, 226-231. doi: 10.1016/j.parint.2010.02.004

Goujon, M., McWilliam, H., Li, W., Valentin, F., Squizzato, S., Paern, J. and Lopez, R. (2010). A new bioinformatics analysis tools framework at EMBL-EBI. Nucleic Acids Research 38 (Web Server issue), W695-699. doi: 10.1093/nar/gkq313.

Guha-Niyogi, A., Sullivan, D. and Turco, S. (2011). Glycoconjugate structures of parasitic protozoa. Glycobiology 11, 45R-59R.

Ha, D. S., Schwarz, J. K., Turco, S. J. and Beverley, S. M. (1996). Use of the green fluorescent protein as a marker in transfected Leishmania. Molecular and Biochemical Parasitology 77, 57-64.

Handa, M. and Guidotti, G. (1996). Purification and cloning of a soluble ATP-diphosphohydrolase (apyrase) from potato tubers (Solanum tuberosum). Biochemical and Biophysical Research Communications 218, 916-923. Herrero, A. B., Uccelletti, D., Hirschberg, C. B., Dominguez, A. and Abeijon, C. (2002). The Golgi GDPase of the fungal pathogen Candida albicans affects morphogenesis, glycosylation, and cell wall properties. Eukaryotic Cell 1, 420-431.

Herwaldt, B. L. (1999). Leishmaniasis. Lancet 354, 1191-1199.

Heussler, V. T., Kuenzi, P. and Rottenberg, S. (2001). Inhibition of apoptosis by intracellular protozoan parasites. International fournal for Parasitology 31, 1166-1176.

Hirschberg, C. B., Robbins, P. W. and Abeijon, C. (1998). Transporters of nucleotide sugars, ATP, and nucleotide sulfate in the endoplasmic reticulum and Golgi apparatus. Annual Review of Biochemistry 67, 49-69. doi: 10.1146/annurev.biochem.67.1.49.

Ivens, A. C., Peacock, C. S., Worthey, E. A., Murphy, L., Aggarwal, G., Berriman, M., Sisk, E., Rajandream, M.A., Adlem, E., Aert, R., Anupama, A., Apostolou, Z., Attipoe, P., Bason, N., Bauser, C., Beck, A., Beverley, S. M., Bianchettin, G., Borzym, K., Bothe, G., Bruschi, C. V., Collins, M., Cadag, E., Ciarloni, L., Clayton, C., Coulson, R.M., Cronin, A., Cruz, A. K., Davies, R. M. De Gaudenzi, J., Dobson, D. E., Duesterhoeft, A., Fazelina, G., Fosker, N., Frasch, A.C., Fraser, A., Fuchs, M., Gabel, C., Goble, A., Goffeau, A., Harris, D., Hertz-Fowler, C., Hilbert, H., Horn, D., Huang, Y., Klages, S., Knights, A., Kube, M., Larke, N., Litvin, L., Lord, A., Louie, T., Marra, M., Masuy, D., Matthews, K., Michaeli, S., Mottram, J.C., Muller-Auer, S., Munden, H., Nelson, S., Norbertczak, H., Oliver, K., O'Neil, S., Pentony, M., Pohl, T. M., Price, C., Purnelle, B., Quail, M. A., Rabbinowitsch, E., Reinhardt, R., Rieger, M., Rinta, J., Robben, J., Robertson, L., Ruiz, J.C., Rutter, S., Saunders, D., Schafer, M., Schein, J., Schwartz, D. C., Seeger, K., Seyler, A., Sharp, S., Shin, H., Sivam, D., Squares, R., Squares, S., Tosato, V., Vogt, C., Volckaert, G., Wambutt, R., Warren, T., Wedler, H., Woodward, J., Zhou, S., Zimmermann, W., Smith, D. F., Blackwell, J. M. Stuart, K. D., Barrell, B. and Myler, P. J. (2005). The genome of the kinetoplastid parasite, Leishmania major. Science 309, 436-442.

Jesus, J. B., Lopes, A. H. and Meyer-Fernandes, J. R. (2002) Characterization of an ecto-ATPase of Tritrichomonas foetus. Veterinary Parasitology 103, 29-42.

Johnson, M. S., Broady, K. W. and Johnson, A. M. (1999). Differential recognition of Toxoplasma gondii recombinant nucleoside triphosphate hydrolase isoforms by naturally infected human sera. International fournal for Parasitology 29, 1893-1905.

Jones, T., Federspiel, N. A., Chibana, H., Dungan, J., Kalman, S., Magee, B. B., Newport, G., Thorstenson, Y. R., Agabian, N. Magee, P. T., Davis, R. W. and Scherer, S. (2004). The diploid genome sequence of Candida albicans. Proceedings of the National Academy of Sciences, USA 101, 7329-7334. doi: 10.1073/pnas.0401648101.

Junior, I. C., Rodrigues, M. L., Alviano, C.S., Travassos, L. R. and Meyer-Fernandes, J. R. (2005). Characterization of an ecto-ATPase activity in Cryptococcus neoformans. FEMS Yeast Research 5, 899-907. Kiffer-Moreira, T., Fernandes Sampaio, M.E., Alviano, D.S., Axelband, F., Cesar, G. V., Cosentino-Gomes, D., Rodrigues, M. L. Nimrichter, L., Vieyra, A., Alviano, C. S. and Meyer-Fernandes, J. R. (2010). Biochemical characterization of an ecto-ATP diphosphohydrolase activity in Candida parapsilosis and its possible role in adenosine acquisition and pathogenesis. FEMS Yeast Research 10, 735-746. doi: 10.1111/ j.1567-1364.2010.00641.x.

Kikuchi, T., Furuta, T. and Kojima, S. (2001). Membrane localization and demonstration of isoforms of nucleoside triphosphate hydrolase from Toxoplasma gondii. Parasitology 122, 15-23.

Knowles, A.F. (2011). The GDA1_CD39 superfamily: NTPDases with diverse functions. Purinergic Signal 7, 21-45. doi: 10.1007/s11302-0109214-7.

Kukulski, F., Bahrami, F., Ben Yebdri, F., Lecka, J., Martin-Satue, M., Levesque, S. A. and Sevigny, J. (2011). NTPDase1 controls IL-8 production by human neutrophils. Fournal of Immunology 187, 644-653 doi: 10.4049/jimmunol.1002680.

Larkin, M. A., Blackshields, G., Brown, N.P., Chenna, R., McGettigan, P.A., McWilliam, H., Valentin, F., Wallace, I. M. Wilm, A., Lopez, R., Thompson, J. D., Gibson, T. J. and Higgins, D. G. (2007). Clustal W and Clustal X version 2.0. Bioinformatics 23, 2947-2948. doi: 10.1093/bioinformatics/btm404.

Leite, M.S., Thomaz, R., Oliveira, J.H., Oliveira, P. L. and Meyer-Fernandes, J.R. (2009). Trypanosoma brucei brucei: effects of ferrous iron and heme on ecto-nucleoside triphosphate diphosphohydrolase activity. Experimental Parasitology 121, 137-143. doi: 10.1016/j. exppara.2008.10.018.

Letunic, I. and Bork, P. (2007). Interactive Tree Of Life (iTOL): an online tool for phylogenetic tree display and annotation. Bioinformatics 23, 127 128. doi: 10.1093/bioinformatics/bt1529.

Letunic, I. and Bork, P. (2011). Interactive Tree Of Life v2: online annotation and display of phylogenetic trees made easy. Nucleic Acids Research 39 (Web Server issue), W475-478. doi: 10.1093/nar/gkr201.

Levano-Garcia, J., Mortara, R. A., Verjovski-Almeida, S. and DeMarco, R. (2007). Characterization of Schistosoma mansoni ATPDase2 gene, a novel apyrase family member. Biochemical and Biophysical Research Communications 352, 384-389.

Levesque, S. A., Kukulski, F., Enjyoji, K., Robson, S. C. and Sevigny, J. 2010). NTPDase1 governs P2X7-dependent functions in murine macrophages. European Fournal of Immunology 40, 1473-1485. doi: 10.1002/ eji.200939741.

Loftus, B. J., Fung, E., Roncaglia, P., Rowley, D., Amedeo, P., Bruno, D., Vamathevan, J., Miranda, M., Anderson, I. J., Fraser, J. A., Allen, J.E., Bosdet, I. E., Brent, M. R., Chiu, R., Doering, T.L., Donlin, M. J., D'Souza, C. A., Fox, D.S., Grinberg, V., Fu, J., Fukushima, M., Haas, B. J., Huang, J. C., Janbon, G., Jones, S. J., Koo, H. L., Krzywinski, M. I., KwonChung, J. K., Lengeler, K. B., Maiti, R., Marra, M. A., Marra, R. E., Mathewson, C. A., Mitchell, T. G., Pertea, M., Riggs, F. R., Salzberg, S. L., Schein, J. E., Shvartsbeyn, A., Shin, H., Shumway, M., Specht, C. A., Suh, B. B., Tenney, A., Utterback, T. R., Wickes, B. L., Wortman, J.R., Wye, N.H., Kronstad, J. W., Lodge, J. K., Heitman, J., Davis, R. W., Fraser, C. M. and Hyman, R. W. (2005). The genome of the basidiomycetous yeast and human pathogen Cryptococcus neoformans. Science 307, 1321-1324. doi: 10.1126/science.1103773.

Lopez-Avalos, M. D., Uccelletti, D., Abeijon, C. and Hirschberg, C. B. (2001). The UDPase activity of the Kluyveromyces lactis Golgi GDPase has a role in uridine nucleotide sugar transport into Golgi vesicles. Glycobiology 11, 413-422.

Luiz Oliveira Penido, M., Resende, D. M., Vianello, M. A., Humberto da Silveira Bordin, F., Jacinto, A.A., Dias, W. D., Montesano, M. A., Nelson, D. L., Marcos Zech Coelho, P. and Vasconcelos, E. G. (2007). A new series of schistosomicide drugs, the alkylaminoalkanethiosulfuric acids, partially inhibit the activity of Schistosoma mansoni ATP diphosphohydrolase. European Fournal of Pharmacology 570, 10-17.

Marcus, A. J., Broekman, M. J., Drosopoulos, J. H., Islam, N., Alyonycheva, T. N., Safier, L.B., Hajjar, K. A., Posnett, D. N., Schoenborn, M.A., Schooley, K. A., Gayle, R.B. and Maliszewski, C. R. (1997). The endothelial cell ecto-ADPase responsible for inhibition of platelet function is CD39. The Fournal of Clinical Investigation 99, 1351-1360.

Marques-da-Silva, C., Chaves, M. M., Chaves, S. P., Figliuolo, V. R., Meyer-Fernandes, J. R., Corte-Real, S., Lameu, C., Ulrich, H., Ojcius, D. M., Rossi-Bergmann, B. and Coutinho-Silva, R (2011). Infection with Leishmania amazonensis upregulates purinergic receptor expression and induces host-cell susceptibility to UTP-mediated apoptosis. Cellular Microbiology 13, 1410-1428. doi: 10.1111/ j.1462-5822.2011.01630.x

Matin, A. and Khan, N. A. (2008). Demonstration and partial characterization of ecto-ATPase in Balamuthia mandrillaris and its possible role in the host-cell interactions. Letters in Applied Microbiology 47, 348-354. doi: 10.1111/j.1472-765X.2008.02414.x

Matthews, K. R. (2005). The developmental cell biology of Trypanosoma brucei. Fournal of Cell Science 118, 283-290.

McMorran, B. J., Marshall, V.M., de Graaf, C., Drysdale, K. E., Shabbar, M., Smyth, G. K., Corbin, J. E., Alexander, W.S. and Foote, S. J. (2009). Platelets kill intraerythrocytic malarial parasites and mediate survival to infection. Science 323, 797-800. doi: 10.1126/ science.1166296.

Meyer-Fernandes, J. R. (2002). Ecto-ATPases in protozoa parasites: looking for a function. Parasitology International 51, 299-303. 
Meyer-Fernandes, J. R., Cosentino-Gomes, D., Vieira, D.P. and Lopes, A. H. (2010). Ecto-Nucleoside Triphosphate Diphosphohydrolase Activities in Trypanosomatids: Possible Roles in Infection, Virulence and Purine Recycling. The Open Parasitology fournal, 4, 116-119.

Meyer-Fernandes, J. R., Dutra, P. M., Rodrigues, C. O., SaadNehme, J. and Lopes, A.H. (1997). Mg-dependent ecto-ATPase activity in Leishmania tropica. Archives of Biochemistry and Biophysics 341, $40-46$.

Meyer-Fernandes, J.R., Saad-Nehme, J., Peres-Sampaio, C.E., Belmont-Firpo, R., Bisaggio, D. F., Do Couto, L. C., Fonseca De Souza, A. L., Lopes, A. H. and Souto-Padron, T. (2004). A Mgdependent ecto-ATPase is increased in the infective stages of Trypanosoma cruzi. Parasitology Research 93, 41-50.

Nakaar, V., Beckers, C. J., Polotsky, V. and Joiner, K. A. (1998a). Basis for substrate specificity of the Toxoplasma gondii nucleoside triphosphate hydrolase. Molecular and Biochemical Parasitology 97, 209-220.

Nakaar, V., Bermudes, D., Peck, K. R. and Joiner, K. A. (1998b). Upstream elements required for expression of nucleoside triphosphate hydrolase genes of Toxoplasma gondii. Molecular and Biochemical Parasitology 92, 229-239.

Nakaar, V., Samuel, B. U., Ngo, E. O. and Joiner, K. A. (1999). Targeted reduction of nucleoside triphosphate hydrolase by antisense RNA inhibits Toxoplasma gondii proliferation. The Fournal of Biological Chemistry 274, 5083-5087.

Okenu, D. M., Opara, K. N., Nwuba, R. I. and Nwagwu, M. (1999). Purification and characterisation of an extracellularly released protease of Trypanosoma brucei. Parasitology Research 85, 424-428.

Paletta-Silva, R. and Meyer-Fernandes, J. R. (2012). Adenosine and immune imbalance in visceral leishmaniasis: the possible role of ectonucleotidases. Fournal of Tropical Medicine 2012, 650874. doi: 10.1155/2012/ 650874 .

Peacock, C. S., Seeger, K., Harris, D., Murphy, L., Ruiz, J. C., Quail, M. A., Peters, N., Adlem, E., Tivey, A., Aslett, M., Kerhornou, A., Ivens, A., Fraser, A., Rajandream, M. A., Carver, T., Norbertczak, H., Chillingworth, T., Hance, Z., Jagels, K., Moule, S., Ormond, D., Rutter, S., Squares, R., Whitehead, S., Rabbinowitsch, E., Arrowsmith, C., White, B., Thurston, S., Bringaud, F., Baldauf, S. L., Faulconbridge, A., Jeffares, D., Depledge, D.P., Oyola, S. O., Hilley, J. D., Brito, L. O., Tosi, L. R., Barrell, B., Cruz, A. K., Mottram, J. C., Smith, D. F. and Berriman, M. (2007). Comparative genomic analysis of three Leishmania species that cause diverse human disease. Nature Genetics 39, 839-847.

Peres-Sampaio, C. E., de Almeida-Amaral, E. E., Giarola, N. L. and Meyer-Fernandes, J.R. (2008). Leishmania amazonensis: effects of heat shock on ecto-ATPase activity. Experimental Parasitology 119, 135-143. doi: S0014-4894(08)00008-8 [pii] 10.1016/j.exppara.2008.01.003. Peres-Sampaio, C.E., Palumbo, S. T. and Meyer-Fernandes, J. R. (2001). An ecto-ATPase activity present in Leishmania tropica stimulated by dextran sulfate. Zeitschrift für Naturforschung, C 56, 820-825.

Pinheiro, C. M., Martins-Duarte, E. S., Ferraro, R. B., Fonseca de Souza, A. L., Gomes, M.T., Lopes, A.H., Vannier-Santos, M. A., Santos, A. L. and Meyer-Fernandes, J. R. (2006). Leishmania amazonensis: Biological and biochemical characterization of ecto-nucleoside triphosphate diphosphohydrolase activities. Experimental Parasitology $114,16-25$

Pizzirani, C., Ferrari, D., Chiozzi, P., Adinolfi, E., Sandona, D., Savaglio, E. and Di Virgilio, F. (2007). Stimulation of P2 receptors causes release of IL-1 \{beta\}-loaded microvesicles from human dendritic cells. Blood 109, 3856-3864.

Robson, S. C., Sevigny, J. and Zimmermann, H. (2006). The ENTPDase family of ectonucleotidases: Structure function relationships and pathophysiological significance. Purinergic Signal 2, 409-430.

Ruckert, C., Stuepp Cdos, S., Gottardi, B., Rosa, J., Cisilotto, J., Borges, F. P., Rosemberg, D. B., Bogo, M. R., Tasca, T., De Carli, G. A. and Bonan, C. D. (2010). Trichomonas vaginalis: dehydroepiandrosterone sulfate and 17beta-estradiol alter NTPDase activity and gene expression. Experimental Parasitology 125, 187-195. doi: 10.1016/j.exppara.2010.01.029.

Sanchez, R., Franco, A., Gacto, M., Notario, V. and Cansado, J. (2003). Characterization of gdp1 + as encoding a GDPase in the fission yeast Schizosaccharomyces pombe. FEMS Microbiology letters 228, 33-38.

Sansom, F. M., Newton, H. J., Crikis, S., Cianciotto, N.P., Cowan, P. J., d'Apice, A. J. and Hartland, E. L. (2007). A bacterial ecto-triphosphate diphosphohydrolase similar to human CD39 is essential for intracellular multiplication of Legionella pneumophila. Cellular Microbiology 9, 1922-1935.

Sansom, F. M., Riedmaier, P., Newton, H. J., Dunstone, M. A., Muller, C. E., Stephan, H., Byres, E., Beddoe, T., Rossjohn, J.,
Cowan, P. J., d'Apice, A. J., Robson, S. C. and Hartland, E. L. (2008a). Enzymatic properties of an ecto-nucleoside triphosphate diphosphohydrolase from Legionella pneumophila: substrate specificity and requirement for virulence. The Fournal of Biological Chemistry 283, 12909-12918. doi: M801006200 [pii]10.1074/jbc.M801006200.

Sansom, F. M., Robson, S. C. and Hartland, E. L. (2008b). Possible effects of microbial ecto-nucleoside triphosphate diphosphohydrolases on host-pathogen interactions. Microbiology and Molecular Biology Reviews 72, 765-781, Table of Contents. doi: 72/4/765 [pii]10.1128/ MMBR.00013-08

Santos, R. F., Possa, M. A., Bastos, M. S., Guedes, P. M. Almeida, M. R., Demarco, R., Verjovski-Almeida, S., Bahia, M. T. and Fietto, J. L. (2009). Influence of Ecto-nucleoside triphosphate diphosphohydrolase activity on Trypanosoma cruzi infectivity and virulence. PLoS Neglected Tropical Diseases 3, e387. doi: 10.1371/journal. pntd.0000387.

Sibley, L.D., Niesman, I. R., Asai, T. and Takeuchi, T. (1994). Toxoplasma gondii: secretion of a potent nucleoside triphosphate hydrolase into the parasitophorous vacuole. Experimental Parasitology 79, 301-311.

Silverman, J.A., Qi, H., Riehl, A., Beckers, C., Nakaar, V. and Joiner, K. A. (1998). Induced activation of the Toxoplasma gondii nucleoside triphosphate hydrolase leads to depletion of host cell ATP levels and rapid exit of intracellular parasites from infected cells. The fournal of Biological Chemistry 273, 12352-12359.

Sissons, J., Alsam, S., Jayasekera, S. and Khan, N. A. (2004). EctoATPases of clinical and non-clinical isolates of Acanthamoeba. Microbial pathogenesis, 37(5), 231-239.

Souza, V. L., Veras, P. S., Welby-Borges, M., Silva, T. M., Leite, B. R., Ferraro, R. B., Meyer-Fernandes, J. R., Barral, A., Costa, J. M. and de Freitas, L.A. (2011). Immune and inflammatory responses to Leishmania amazonensis isolated from different clinical forms of human leishmaniasis in CBA mice. Memorias do Instituto Oswaldo Cruz 106, 23-31.

Spath, G. F., Epstein, L., Leader, B., Singer, S. M., Avila, H. A., Turco, S. J. and Beverley, S. M. (2000). Lipophosphoglycan is a virulence factor distinct from related glycoconjugates in the protozoan parasite Leishmania major. Proceedings of the National Academy of Sciences, USA 97 9258-9263. doi: 10.1073/pnas.160257897.

Stanley, R. G., Ngaiza, J. R., Wambayi, E., Lewis, J. and Doenhoff, M. J. (2003). Platelets as an innate defence mechanism against Schistosoma mansoni infections in mice. Parasite Immunology 25, 467-473.

Stommel, E. W., Cho, E., Steide, J. A., Seguin, R., Barchowsky, A., Schwartzman, J. D. and Kasper, L. H. (2001). Identification and role of thiols in Toxoplasma gondii egress. Experimental Biology and Medicine 226, 229-236.

Stommel, E. W., Ely, K. H., Schwartzman, J. D. and Kasper, L. H. (1997). Toxoplasma gondii: dithiol-induced Ca2 + flux causes egress of parasites from the parasitophorous vacuole. Experimental Parasitology 87, 88-97.

Tanowitz, H. B., Burns, E. R., Sinha, A. K., Kahn, N. N., Morris, S. A., Factor, S. M., Hatcher, V.B., Bilezikian, J.P., Baum, S. G. and Wittner, M. (1990). Enhanced platelet adherence and aggregation in Chagas' disease: a potential pathogenic mechanism for cardiomyopathy. The American Fournal of Tropical Medicine and Hygiene 43, 274-281.

Tasca, T., Bonan, C. D., De Carli, G. A., Sarkis, J. J. and Alderete, J. F. (2005). Heterogeneity in extracellular nucleotide hydrolysis among clinical isolates of Trichomonas vaginalis. Parasitology 131, 71-78.

Taylor, M. C., Huang, H. and Kelly, J. M. (2011). Genetic techniques in Trypanosoma cruzi. Advances in Parasitology 75, 231-250. doi: 10.1016/ B978-0-12-385863-4.00011-3.

Umekita, L. F., Piazza, R. M. and Mota, I. (1994). Role of platelets and complement in the clearance of epimastigote forms of Trypanosoma cruzi. Brazilian Fournal of Medical and Biological Research 27, 2391-2399. Van der Pol, B. (2007). Trichomonas vaginalis infection: the most prevalent nonviral sexually transmitted infection receives the least public health attention. Clinical Infectious Diseases 44, 23-25.

Vasconcelos, E. G., Ferreira, S. T., Carvalho, T. M., Souza, W., Kettlun, A. M., Mancilla, M., Valenzuela, M. A. and VerjovskiAlmeida, S. (1996). Partial purification and immunohistochemical localization of ATP diphosphohydrolase from Schistosoma mansoni. Immunological cross-reactivities with potato apyrase and Toxoplasma gondi nucleoside triphosphate hydrolase. The Gournal of Biological Chemistry 271 22139-22145.

Vasconcelos, E. G., Nascimento, P.S., Meirelles, M. N., VerjovskiAlmeida, S. and Ferreira, S. T. (1993). Characterization and localization of an ATP-diphosphohydrolase on the external surface of the tegument 
of Schistosoma mansoni. Molecular and Biochemical Parasitology 58, 205-214.

Vivian, J.P., Riedmaier, P., Ge, H., Le Nours, J., Sansom, F. M., Wilce, M. C., Byres, E., Dias, M., Schmidberger, J. W., Cowan, P. J. d'Apice, A. J., Hartland, E. L., Rossjohn, J. and Beddoe, T. (2010) Crystal structure of a Legionella pneumophila ecto-triphosphate diphosphohydrolase, a structural and functional homolog of the eukaryotic NTPDases. Structure 18, 228-238. doi: S0969-2126(09)00480-8 [pii] 10.1016/j.str.2009.11.014.
Zhang, D., Gaji, R. Y. and Howe, D. K. (2006). Identification of a dithioldependent nucleoside triphosphate hydrolase in Sarcocystis neurona. International Fournal for Parasitology 36, 1197-1204.

Zimmermann, H., Beaudoin, A. R., Bollen, M., Goding, J. W., Guidotti, G., Kirley, T. L., Robson, S. C. and Sano, K (2000) Nomenclature for two families of novel ecto-nucleotidases. In Second International Workshop on Ecto-ATPases and Related Ecto-nucleotidases (ed. Vanduffel, L. and Lemmens, R.), pp. 1-8. Shaker Publishing BV, Maastricht, The Netherlands. 


\section{University Library}

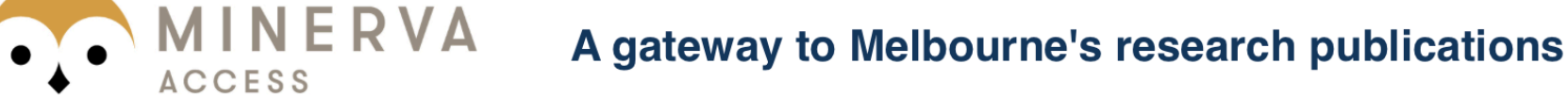

Minerva Access is the Institutional Repository of The University of Melbourne

Author/s:

Sansom, FM

Title:

The role of the NTPDase enzyme family in parasites: what do we know, and where to from here?

Date:

2012-07-01

Citation:

Sansom, F. M. (2012). The role of the NTPDase enzyme family in parasites: what do we know, and where to from here?. PARASITOLOGY, 139 (8), pp.963-980. https:// doi.org/10.1017/S003118201200025X.

Publication Status:

Accepted manuscript

Persistent Link:

http://hdl.handle.net/11343/41944 